$$
\begin{gathered}
\text { UNIVERSIDADE DE BRASÍLIA } \\
\text { FACULDADE DE EDUCAÇÃO FÍSICA } \\
\text { PROGRAMA DE PÓS-GRADUAÇÃO STRICTU-SENSU }
\end{gathered}
$$

EM EDUCAÇÃO FÍSICA

\author{
EFEITOS DO TREINAMENTO RESISTIDO DE ALTA INTENSIDADE NO \\ PERFIL PROTEÔMICO DO \\ MÚSCULO GASTROCNÊMIO DE RATOS VELHOS
}

Marcia Mendes Carvalho

BRASÍLIA 


\title{
EFEITOS DO TREINAMENTO RESISTIDO DE ALTA INTENSIDADE NO PERFIL PROTEÔMICO DO MÚSCULO GASTROCNÊMIO DE RATOS VELHOS
}

\author{
Marcia Mendes Carvalho
}

\begin{abstract}
Dissertação apresentada à Faculdade de Educação Física da Universidade de Brasília, como requisito parcial para a obtenção do grau de Mestre em Educação Física.
\end{abstract}

Orientador: Prof. Dr. João Luiz Quagliotti Durigan 
DEDICATÓRIA

À minha mãe, Silvia Maria. 


\section{AGRADECIMENTOS}

Á Deus, causa primária de todas as coisas.

Agradeço a Mamãe, Aninha e Rafael, por serem minha amada família. Obrigada pelo apoio incondicional. Amo vocês.

Ao Manoel Benício e Fabrício Barin, por serem amigos que guardo no fundo do coração.

Ao Orientador. Agradeço ao Prof. Dr. João Durigan, que me orientou, apesar das minhas dificuldades e trabalhou com muita paciência, para que eu pudesse desenvolver minhas potencialidades.

Ao Prof. Jeeser Almeida. Mestre e Amigo. Obrigada por me mostrar que a calma e dedicação levam a resultados incríveis. Agradeço os ensinamentos diários de risos e conhecimento.

À Prof. Dra. Rita de Cássia, pelo conhecimento compartilhado e colocações sempre assertivas.

Ao Prof. Dr. Luiz Octávio Franco, por me receber no laboratório e, pelo exemplo, me ensinar que mentes geniais também possuem corações gigantes.

Aos amigos do Laboratório de Análises Proteômicas e Bioquímicas da Universidade Católica de Brasília (CAPB). Agradeço imensamente ao Júnior, Betty, Ana Paula, Mirna, Ludovico, Kléber, Flávia Dutra, Stella, Dan, Stephan, Maurício, Loiane, Kênia e demais membros do CAPB, por terem sido tão maravilhosos e pacientes. Vocês são incríveis.

À Eliene, Gleyce e Ivo, pela oportunidade de ensinar e aprender.

À Karenina, pela amizade que alegra os meus dias. 
Aos amigos do CNPq, Ângela Melo, Silvio, Samuel, Fábio, Raphael, Vanessinha e Larissa, que sempre acreditaram que eu pudesse chegar o mais longe possível.

Aos membros do GPLAST, pelo apoio e aprendizado conjunto.

Aos demais amigos e colegas que contribuíram com mais esta conquista. Muito Obrigada.

À Universidade de Brasília e a CAPES pelo apoio financeiro concedido. 
LISTA DE FIGURAS ................................................ viii

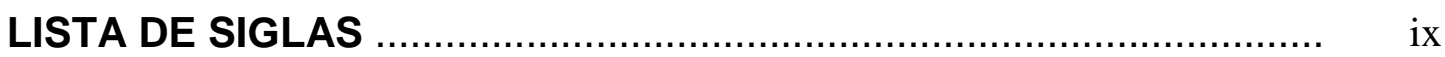

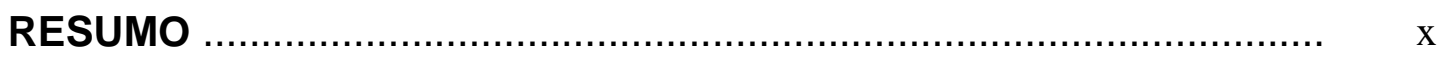

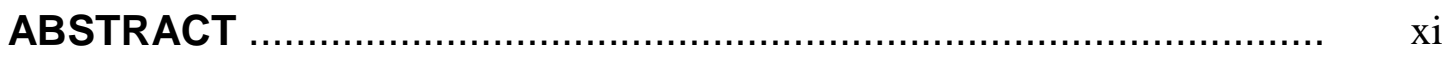

1. INTRODUÇÃO .................................................................. 12

2. REVISÃO DE LITERATURA ................................................. 14

2.1 Características do Tecido músculoesquelético............................... 14

2.2 Envelhecimento e Sarcopenia................................................. 16

2.3 Treinamento resistido e Envelhecimento.................................... 17

2.4 Proteômica.............................................................................. 19

2.4.1. Proteômica e Envelhecimento.................................................. 21

2.4.2. Proteômica e Exercício................................................................ 23

3.0 OBJETIVOS ................................................................. 25

4.0 MATERIAL E MÉTODOS ….................................................. 26

4.1 Animais .............................................................................. 26

4.2 Grupos experimentais.......................................................... 26

4.3 Treinamento Resistido ........................................................ 26

4.3.1 Familiarização. ................................................................... 26

4.3.2 Determinação da capacidade de carga máxima ....................... 27

4.3.3 Período de treinamento resistido.................................................. 28

4.3.4 Coleta do músculo e avaliação de área de secção transversa......... 28

4.4 Extração e quantificação de proteínas........................................... 29

4.4.1 Preparação da amostra para a aquisição por LC-ESI-MS / MS...... 29

4.4.2 Aquisição e processamento de dados por LC-ESI-MS / MS........... 30

4.4.3 Quantificação de proteínas por LC-MS ..................................... 31

5.0 Análise estatística..................................................................... 32 


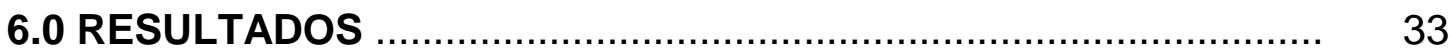

6.1 Capacidade de carregamento máximo...................................... 33

6.2 Dados qualitativos LC/MS ................................................... 33

6.2.3 Abundância de proteínas no envelhecimento............................. 35

6.2.4 Abundância e proteínas após Treinamento resistido..................... 36

6.2.5 Abundância de proteínas no músculo idoso após Treinamento

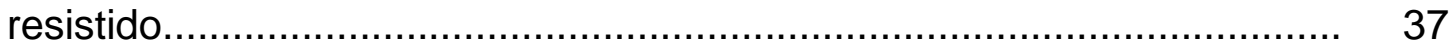

6.3 Área de secção Transversa (AST) ........................................... 39

7.0 DISCUSSÃO .............................................................................. 40

8.0 CONCLUSÃO .............................................................................. 45

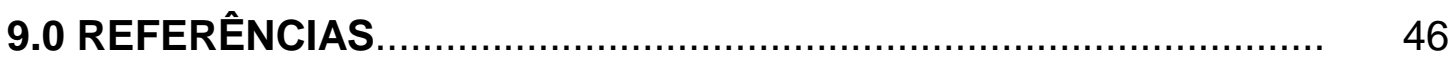

ANEXO I - Aprovação do Comitê de Ética em Experimentação Animal............................................................................................ 53

APÊNDICE I - Proteínas expressas e alteradas pelo envelhecimento no músculo gastrocnêmio, agrupadas de acordo com suas funções biológicas. APÊNDICE II - Proteínas expressas alteradas pelo treinamento resistido no músculo gastrocnêmio, agrupados de acordo com suas funções biológicas. APÊNDICE III - Proteínas expressas alteradas no músculo gastrocnêmio de ratos velhos após treinamento resistido, agrupados de acordo com suas funções biológicas. 


\section{LISTA DE FIGURAS}

Página

Figura 1 - Metodologias utilizadas nos estudos proteômicos.

Figura 2 - Modelo de escada para o protocolo de treinamento resistido (TR)

Figura 3 - Classificação de proteínas de acordo com o processo biológico, função molecular e componente celular.

Figura 4 - Diagrama de Venn

Figura 5A - Histograma da abundância de proteínas entre o grupo sedentário jovem (SJ) e sedentário velho (SV)

Figura 5B - Histograma da abundância de proteínas entre o grupo sedentário jovem (SJ) e treinado jovem (TJ).

Figura 5C - Histograma da abundância de proteínas entre o grupo sedentário velho (SV) e treinado velho (TV)

Figura 6 - Área de secção transversa (AST) apresentadas em distribuição $\left(\mu \mathrm{m}^{2}\right)$ e número de observações (\%) do músculo gastrocnêmio nos grupos sedentário jovem (SJ), treinado jovem (TJ), sedentário velho (SV) e treinado velho (TV) 


\section{LISTA DE SIGLAS}

$\begin{array}{ll}\text { ADP } & \text { adenosina difosfato } \\ \text { AST } & \text { área de secção transversa } \\ \text { ATP } & \text { adenosina trifosfato } \\ \text { CAH } 3 & \text { anidrase carbônica 3 } \\ \text { COL1A1 } & \text { colágeno alfa 1 } \\ \text { ENOB } & \text { beta-enolase } \\ \text { G3P } & \text { gliceraldeído-3-fosfato dehidrogenase } \\ \text { G6PI } & \text { glucose-6-fosfato isomerase } \\ \text { HBA } & \text { hemoglobina subunidade alfa 1/2 } \\ \text { HBB1 } & \text { hemoglobina subunidade beta 1 } \\ \text { KCRM } & \text { creatina cinase tipo M } \\ \text { LDHA } & \text { L-lactato dehidrogenase cadeia A } \\ \text { MLRS } & \text { cadeia leve de miosina 2 } \\ \text { MYG } & \text { mioglobina } \\ \text { MYH4 } & \text { miosina-4 } \\ \text { MYL1 } & \text { cadeia leve de miosina 1/3 } \\ \text { PARK7 } & \text { proteína deglicase DJ 1 } \\ \text { PGAM2 } & \text { fosfoglicerato mutase 2 } \\ \text { PGK1 } & \text { fosfoglicerato cinase 1 } \\ \text { PGM1 } & \text { fosfoglucomutase 1 } \\ \text { PRDX1 } & \text { peroxiredoxina 1 } \\ \text { PRDX6 } & \text { peroxiredoxina 6 } \\ \text { RF1ML } & \text { fator de liberação de cadeia peptídica 1, mitocondrial } \\ \text { RS27A } & \text { ubiquitina-40s proteina ribosomal S27a } \\ \text { SODC } & \text { Cobre-zinco superóxido dismutase } \\ \text { TPIS } & \text { triosefosfato isomerase } \\ \text { TRFE } & \text { serotransferrina } \\ \text { O } & \text { oxigênio } \\ \text { Ca } & \text { cálcio }\end{array}$




\section{RESUMO}

A sarcopenia é um processo multifatorial caracterizado pela perda da força e de massa do músculo esquelético, o que leva à redução da área de secção transversa (AST) muscular. O treinamento resistido (TR) é uma ferramenta importante para reduzir a sarcopenia, porém, a análise proteômica do músculo de ratos velhos após TR ainda é pouco estudado. O objetivo do presente estudo foi analisar o perfil proteômico do músculo gastrocnêmio de ratos jovens e velhos após o TR. Vinte e quatro Rattus norvegicus com 3 meses $(298,74 \pm 32,32 \mathrm{~g})$ e 21 meses $(517,83 \pm 76,30 \mathrm{~g})$ de idade foram divididos em grupo sedentários jovens ( $S J, n=6)$, treinados jovens (TJ, $n=$ $6)$, sedentários velhos (SV, $n=6$ ) e treinados velhos (TV, $n=6$ ). Foram realizados 12 semanas de treinamento resistido, que consistiam em subir uma escada vertical $\left(1,1 \mathrm{~m}, 0,18 \mathrm{~m}, 2 \mathrm{~cm}\right.$ entre as grades e $80^{\circ}$ de inclinação) com uma carga fixada na cauda do animal. As cargas eram definidas de acordo com a capacidade de carregamento dos animais e aumentadas progressivamente com 65, 85, 95 e 100\% da capacidade de carga máxima de carregamento de cada animal. $\mathrm{O}$ tamanho da escada induzia os animais a realizar de 8 a 12 movimentos por subida, sendo o TR realizado três vezes por semana (segundas, quartas e sextas-feiras) durante 12 semanas. Após a última sessão de treino, o músculo gastrocnêmio foi extraído e os compostos proteicos foram analisados por cromatografia líquida acoplada a uma fonte de ionização por Electrospray tandem Espectrometria de Massas (LC-ESI-MS/MS). As amostras foram identificadas utilizando banco de dados UniProt / Swissprot. As proteínas foram consideradas reguladas, quando o escore dos peptídeos esteve maior que o escore mínimo para o limite de confiança de $95 \% \quad(p<0.05)$. A normalidade dos dados foi testada utilizando o teste de Shapiro-Wilk e Levene $(p>0,05)$ e os dados apresentados em média e desvio padrão. Foram identificadas 131 proteínas, sendo que 28 destas foram comuns a todos os grupos. 12 semanas de treinamento resistido em ratos modula proteínas que favorecem as adaptações celulares benéficas ao exercício. Porém, a inatividade, representada pelo sedentarismo, promove aumento de proteínas que podem levar ao maior comprometimento do tecido muscular.

Palavras - chave: sarcopenia, treinamento de foça, proteômica, LC-ESIMS/MS. 


\begin{abstract}
Sarcopenia is a multifactorial process characterized by loss of strength and skeletal muscle mass, which leads to a reduction of muscle cross-sectional area (CSA). Resistance training (RT) have been indicated as an import tool to reduce sarcopenia. The aim of the present study was to analyze the effect of RT on gastrocnemius proteome profile of old rats. Twenty-four Rattus norvegicus with 3 months $(298,74 \pm 32,32 \mathrm{~g})$ and 21 months $(517,83 \pm$ $76,30 \mathrm{~g}$ ) were divided into young sedentary ( $\mathrm{YS}, \mathrm{n}=6$ ), young trained ( $\mathrm{YT}, \mathrm{n}$ $=6$ ), old sedentary (OS, $n=6$ ) and old trained (OT, $n=6$ ). Twelve-weeks of resistance training period was performed, which consisted of climbing a vertical ladder $\left(1.1 \mathrm{~m}, 0.18 \mathrm{~m}, 2-\mathrm{cm}\right.$ grid, $80^{\circ}$ incline) with a load secured to their tails. The size of the ladder induced the animals to perform 8-12 movements per climb. TF was carried out three times a week (Mondays, Wednesdays and Fridays) for 12 weeks. The length of the ladder allowed the animals did 8-12 dynamic movements of ascent. The climbs were to carry a progressive load of $65,85,95$ and $100 \%$ of the maximum load capacity of each animal. Gastrocnemius muscle was extracted and protein compounds were analyzed by liquid chromatography coupled to electrospray ionization tandem mass spectrometry (LC-ESI-MS/MS). Samples were identified using Uniprot / Swissprot database. One-hundred and third-one proteins were identified, 28 were between all groups. Aging and RT up-regulated proteins related to transport, cytoprotection, structural and metabolic functions, showing alterations due sarcopenia process and exercise. Interestingly, RT down-regulated structural, transport and metabolic proteins in aged rats. RT induced an increase in muscle CSA of OS and OT groups. In conclusion, RT reduced muscle atrophy through the regulation of stress response and by increasing proteins related with energy production and microcirculation, which in turn might protect tissue damage arising from exercise and aging.
\end{abstract}

Key words: sarcopenia; resistance training; proteomic; LC-ESI-MS/MS 


\section{INTRODUÇÃO}

A incapacidade durante o envelhecimento é acompanhada por altos níveis de fragilidade e quedas (Nilwik et al, 2013). A sarcopenia associada com o envelhecimento é considerada um processo multifatorial, que leva à redução do conteúdo proteico muscular, área de secção transversa (AST) e força muscular (Gelfi, et al, 2006; Nilwik et al, 2013). Vários estudos têm mostrado que durante 0 envelhecimento, 0 estresse oxidativo, a carbonilação protéica, danos estruturais e proteínas metabólicas são aumentados (O'Connell, Ohlendieck, 2009; Gelfi et al, 2011; Lourenço dos Santos et al, 2015). Porém, há uma diminuição das proteínas sarcoméricas e filamentosas que são importantes para o mecanismo protetor das fibras musculares (Doran et al, 2008; Lourenço dos Santos et al, 2015).

É bem conhecido que o treinamento resistido (TR) promove a hipertrofia pelo aumento da síntese de proteína, e consequentemente da AST das fibras musculares (Verdijk et al, 2009; Mitchell et al, 2013), que podem reduzir os efeitos deletérios da sarcopenia. Embora os efeitos do TR na massa muscular e força sejam descritos em jovens e velhos, os mecanismos moleculares exatos responsáveis por essas modificações ainda não foram totalmente determinados (Mitchell et al, 2014).

A análise proteômica baseada na espectrometria de massas (MS/MS) tem sido usada para caracterizar o proteoma do músculo esquelético, representando uma abordagem relevante para o entendimento das alterações moleculares no músculo esquelético induzido pelo exercício (Petriz et al, 2012). Interessantemente, a proteômica determina a abundância de um grande número de proteínas simultaneamente, enquanto immunoblotting pode ser usada somente para analisar proteínas alvo que são escolhidas com base na sua importância previamente identificada (ou especulada) para uma adaptação fisiológica (Ohlendieck, 2010).

Estudos buscam estabelecer mapas proteômicos no músculo esquelético que podem servir como ponto de partida para pesquisas mais específicas sobre o envelhecimento e exercício. Assim, resultados de mapas proteômicos mostram alterações dependentes da idade que favorecem 0 
estresse oxidativo, pelo aumento das proteínas de estresse $\alpha \beta$ cristalina e HSP27 (Doran et al, 2007), além de predominância de proteínas características de fibras lentas, como mioglobina e anidrase carbônica e diminuição de proteínas de contração rápida, como a beta enolase, sugerindo alteração de composição de fibras dependentes da idade (Gelfi et al, 2006).

Sietsema et al, 2010, analisaram amostras de plasma no músculo esquelético de indivíduos jovens após exercício agudo de rosca bíceps (flexão e extensão de cotovelo) e mostraram aumento de proteínas de transporte (hemoglobina e mioglobina) e proteínas anti-inflamatórias (C-1 inibidor de protease), como potenciais marcadores de lesão muscular. Os resultados do TR em excesso resultam na peroxidação lipídica do músculo esquelético e aumento de espécies reativas de oxigênio (EROs), como observado pelo aumento da abundância de superóxido dismutase mitocondrial, peroxiredoxina 3 e aldeído desidrogenase em ratos (Gandra et al, 2012). Unido á isso, o processo inflamatório desencadeado por microlesôes também favorece liberação de proteínas intracelulares como a mioglobina e creatina quinase (Silva, Macedo, 2011). Ainda assim, Radák et al, 2002 demonstrou que, após o TR, pode ocorrer o aumento do reparo do DNA e resistência do músculo de ratos velhos aos danos advindos do estresse oxidativo.

Apesar desses achados, pouco se sabe sobre o potencial efeito do TR no perfil proteômico do músculo esquelético de ratos velhos. Portanto, nós propomos este estudo para descrever a abundância de proteínas após o TR com dados proteômicos de ratos jovens e velhos treinados. Com isso, o objetivo do estudo foi analisar o efeito da TR no perfil proteômico do músculo gastrocnêmio e AST de ratos jovens e velhos. Além disso, também avaliamos a identificação global de proteínas baseado na abundância dessas proteínas frente ao envelhecimento e TR. A hipótese inicial é que o TR gera respostas benéficas na síntese de proteínas da maquinaria contrátil, metabólicas, proteínas de transporte e antioxidantes no músculo de ratos velhos. 


\section{REVISÃO DE LITERATURA}

\subsection{Características do Tecido Musculoesquelético}

A maior parte dos tecidos presentes nos vertebrados é formada pelo tecido muscular esquelético, que está envolvido na locomoção, postura e movimento respiratório (Silva, Carvalho, 2007). A unidade funcional do músculo esquelético é a fibra muscular, que, dispostas paralelamente, formam feixes de fibras ou fascículos (Saladin et al, 2003). Ao longo de todo comprimento da fibra muscular encontramos o sarcoplasma, constituído por miofibrilas e organelas (Saladin, 2003). As miofibrilas são estruturas da fibra muscular orientadas longitudinalmente, compostas por filamentos finos (proteínas actina, tropomiosina e troponina) e filamentos grossos (proteína miosina), paralelos entre si, formando feixes claros e escuros que se agrupam e caracterizam o tecido muscular estriado esquelético. 0 agrupamento desses miofilamentos dá origem ao sarcômero, a unidade contrátil fundamental da fibra muscular.

Ao redor de cada fibra muscular é observado a matriz extracelular (MEC) rica em proteínas e carboidratos. A MEC muscular apresenta-se formando o epimísio, constituído pelo colágeno tipo I, contínua ao tendão, que envolve o músculo por inteiro; o perimísio, com abundância de colágeno tipo III, que une as fibras musculares em feixes, chamados fascículos e que transmitem força de tensão e o endomísio, formado por colágeno tipo $V$ que envolve cada fibra, permitindo o movimento durante a contração muscular (Kjaer, 2004; Narici et al, 2008). Essa organização das fibras de colágeno é importante para a resistência à tração e conservação da integridade física do músculo durante a contração (Järvinen et al., 2003).

O processo de contração muscular se dá pela interação entre as moléculas de actina e miosina, sendo suas isoformas responsáveis pela força e velocidade durante a contração muscular (Saladin, 2003). Fisiologicamente, essas isoformas de miosina são heterogêneas e estão presentes na porção da cadeia pesada da molécula (MHC). As diferentes isoformas de MHC no músculo, fornecem tipos diferentes de fibras, como as 
fibras lentas do tipo I, com MHCI $\beta$ e fibras rápidas, do tipo IIA com MHClla e do tipo IIB com MHCllb (Pette, Minamoto, 2005). A heterogeneidade molecular das fibras contráteis ocorre devido às diferentes funções metabólicas, bioquímicas e fisiológicas, que conferem ao músculo elevado grau de plasticidade (Ohlendieck, 2011).

Em relação às propriedades bioquímicas, toda energia necessária para as funções celulares, incluindo atividade contrátil, é fornecida pela hidrólise de ATP para ADP e Pi (fosfato inorgânico). O consumo de ATP varia com o tipo de fibra, sendo necessários mecanismos eficientes para sua ressíntese. Esses mecanismos são a atividade da creatina cinase (CK), glicólise e fosforilação oxidativa mitocondrial (Saladin, 2003). A CK é associada à rápida regeneração de ATP, pois, junto com a fosfocreatina (PCr), evita o acúmulo de ADP. Porém, esse sistema possui baixa capacidade de regeneração de ATP. A glicólise é, provavelmente, o sistema mais bem caracterizado nos organismos e é responsável pelo metabolismo de glicogênio e glicose, que tem como produtos o piruvato e o lactato, com grande capacidade de regenerar ATP quando comparado ao sistema PCrCK. Já a fosforilação oxidativa mitocondrial é caracterizada por uma potência ainda mais baixa, mas com grande capacidade de regeneração do ATP, utilizando Acetil-CoA como substrato fornecido pelo piruvato, ácidos graxos e corpos cetônicos (Ohlendieck, 2011).

As fibras musculares são também classificadas pelo tipo de metabolismo que possuem, podendo gerar ATP pelo processo mitocondrial oxidativo, outras fibras através do processo glicolítico e as intermediárias por ambos os mecanismos (Frontera, Ochala, 2015). Baseado nas propriedades bioquímicas, cada tipo de fibra utiliza em maior quantidade um tipo de metabolismo, dependendo da velocidade de contração. Portanto, as fibras foram classificadas em fibras tipo I (lento, oxidativo, resistentes à fadiga), IIA (rápido, oxidativo, propriedades metabólicas intermediária), e IIB (mais rápido, glicolitica e fatigável) (Frontera, Ochala, 2015). 


\subsection{Envelhecimento e Sarcopenia}

O envelhecimento é resultado de um conjunto de processos que ocorrem no organismo vivo que, com o tempo, reduzem sua capacidade de adaptação, gerando comprometimento funcional (Gault, Willems, 2013). Muitos mecanismos são propostos para explicar as causas do envelhecimento, porém, a participação exata de cada um ainda é pouco estudada. O processo de envelhecimento é influenciado por fatores como exercício, nutrição, estresse oxidativo, inflamação e mudanças hormonais (Gault, Willems, 2013). Muitas vezes, essa condição vem acompanhada por alterações não apenas estruturais, mas também pela presença de doenças e redução da função muscular, que é considerada um fator clínico importante para a avaliação da severidade no processo de sarcopenia relacionado à idade (Cederholm, 2011).

A Sarcopenia é uma síndrome multifatorial que tem como característica principal, a perda global de massa e força muscular, o que gera implicações para saúde do idoso e contribui para a perda funcional e pode levar à morte prematura (Doran et al, 2008). Após os 50 anos de idade, há uma redução progressiva de massa muscular de 1 a $2 \%$ ao ano. Similarmente, a força também reduz 3\% ao ano após os 60 anos de idade, enquanto a área de secção transversa do músculo esquelético é reduzida cerca de 25 a 30\% ao ano após os 70 anos de idade (Doria et al, 2012).

A perda de massa muscular tem sido relacionada com a atrofia das fibras, afetando, preferencialmente, as fibras rápidas do tipo II (Narici e Mafulli, 2010). Essa atrofia pode ser causada pela redução da ativação e proliferação de células satélite, redução de fatores de crescimento insulínico (IGF-1), aumento de citocinas pró-inflamatórias como o IL-6 e, inflamações crônicas advindas de doenças associadas ao envelhecimento (Lee et al, 2006; Ibebunjo et al, 2013). Além disso, com o avançar da idade, a capacidade de reinervação também é reduzida, o que implica em redução de unidades motoras e alterações nas junções neuromusculares, levando a processos de apoptose e substituição do tecido muscular por tecido fibroso (Mann et al, 2011; Yu, 2015). Associado a isso, os aspectos de arquitetura 
muscular, composição das fibras e alteração de metabolismo também afetam o processo de acoplamento excitação-contração e a transmissão neuromuscular (Lee et al, 2006)

A força e função musculares estão associadas à menor capacidade de contração do músculo devido à redução da área de secção transversa muscular (AST), que apresenta declínio durante o envelhecimento (Rachel et al, 2013), e devido à presença de tecidos não contráteis, como o conjuntivo e adiposo, que afetam a qualidade de contração (Ibebunjo et al, 2013).

O músculo esquelético é o maior consumidor de oxigênio no corpo e, durante o envelhecimento, ocorrem modificações do mecanismo de defesas antioxidantes e aumento progressivo de espécies reativas de oxigênio (EROs). A produção de EROs pelas mitocôndrias produzidas durante 0 metabolismo energético muscular podem danificar as proteínas, as membranas e o DNA, o que dificulta a capacidade da mitocôndria para sintetizar ATP e realizar suas funções metabólicas (Doria et al, 2012).

Todos esses fatores citados, associados à redução da atividade física, afetam a estrutura e função dos tecidos, tornando-os menos resistentes a perturbações induzidas por doenças ou lesões (Lee et al, 2006; Doria et al, 2012).

\subsection{Treinamento Resistido e envelhecimento}

A prática de exercícios de forma regular traz muitos benefícios para a saúde, como a melhora do desempenho e longevidade, o que reduz o risco de doenças cardiovasculares, câncer e diabetes. Embora o exercício tenha impacto de forma sistêmica, sabe-se que os principais impactos resultam diretamente nas adaptações do músculo esquelético (Powers, Jackson, 2008; Yan et al, 2011). O músculo esquelético humano tem um elevado grau de plasticidade na sua resposta adaptativa a estímulos externos. Esses estímulos alteram a homeostase celular, levam a alterações estruturais e funcionais e impactam diretamente o fenótipo dos tecidos (Pastoris et al, 2000). 
O treinamento do músculo esquelético pode ser feito pelo treinamento de resistência (endurance) ou treinamento resistido (força). O treinamento de resistência tem como objetivo a melhora da capacidade aeróbia, caracterizado por atividades com frequência diária, intensidade vigorosa e duração de, pelo menos, 30 minutos por dia (Williams et al, 2002; Freiberger et al, 2011). Já o treinamento resistido (TR) é direcionado a capacidade de geração de força no músculo esquelético, caracterizado por atividades com frequência de pelo menos 3 vezes por semana, com cargas progressivas e com poucas repetições, porém, com alta intensidade (Freiberger et al, 2011).

O TR é reconhecido como uma estratégia segura e eficaz para melhorar o sistema neuromuscular de idosos adultos, melhorando a força e potência muscular, bem como a capacidade de realizar tarefas funcionais, que podem contribuir para a prevenção de quedas e manutenção de independência (Monteiro, 2013; Stewart et al, 2014). Nesse sentido, estudos mostram que indivíduos idosos, a partir dos 75 anos de idade, ainda possuem a capacidade de hipertrofia e força após TR, mesmo com algumas metodologias de treino diferentes (Mayer et al, 2011; Stewart et al, 2014).

O TR favorece o aumento da capacidade de geração de força muscular por meio da melhora das funções neurais, aumento de síntese de proteínas e ativação de células satélite (Petrella et al, 2006). A melhora da capacidade neural após o TR se dá por meio do melhor recrutamento de unidades motoras e no aumento na frequência de disparo dessas unidades motoras, como já demonstrado por Hakkinen et al, 2001. O aumento da síntese de proteínas é favorecido pelo aumento da fosforilação de genes hipertróficos como o IGF-1 e P70S6K, que podem sinalizar as células satélite a se proliferarem e formar novas miofibrilas, favorecendo aumento da AST muscular (Petrella et al, 2006; Mitchell et al, 2013).

É bem conhecido que o TF leva a microlesões que causam rupturas da matriz extracelular e sarcolema, o que leva a liberação de proteínas intracelulares como mioglobina, lactato desidrogenase, aspartato desidrogenase e creatina cinase, podendo causar danos ao material contrátil (Silva, Macedo,2011). Essas microlesôes levam a respostas inflamatórias, cuja função é a limpeza e reparo dos tecidos danificados. O reparo tecidual é 
um evento acompanhado pela presença de peroxidação lipídica do músculo esquelético e aumento de espécies reativas de oxigênio (EROs), bem como a liberação de citocinas como o fator de necrose tumoral-alfa (TNF- $\alpha$ ) e a interleucina-6 (IL-6) (Silva, Macedo,2011). Após exercício agudo de rosca bíceps (flexão e extensão de cotovelo) em jovens, foi observado aumento de proteínas de transporte (hemoglobina e mioglobina) e proteínas antiinflamatórias (C-1 inibidor de protease), como potenciais marcadores de lesão muscular (Sietsema et al, 2010). Porém, o TR tem a capacidade de reduzir o estresse oxidativo pelo aumento da capacidade oxidativa muscular, bem como aumento da capacidade antioxidante, causadas pela redução do número de lesões celulares (Radák et al, 2002).

Portanto, o TR influencia na saúde e qualidade de vida do idoso, pois promove alterações intracelulares que favorecem a hipertrofia, aumento de força e resistência (Rockl et al, 2008; Carvalho et al, 2012), sendo considerado apropriado para reverter ou reduzir algumas alterações fisiológicas decorrentes do processo de envelhecimento (Williams et a, 2002; Freiberger et al, 2011).

\subsection{Proteômica}

A investigação de processos de doenças e saúde e suas respectivas vias de sinalização e mecanismos estão em foco nos dias atuais. Novas tecnologias surgem com o objetivo de identificar e entender as adaptações decorrentes dos processos fisiológicos ou patológicos. Uma dessas ferramentas em foco atualmente é a proteômica, que tem como principal objetivo, estudar todo o conteúdo de proteínas expressas em uma amostra biológica dentro de uma determinada condição. O conjunto dessas proteínas expressas é denominado proteoma (Sabidó et al, 2012). Com a padronização dos estudos genômicos e transcriptômicos, o estudo de todas as proteínas codificadas pelo genoma é um desafio, visto que variam em resposta a muitos fatores fisiológicos ou patológicos (Baraibar et al, 2013).

A análise proteômica pode ser empregada de diversas formas, como por exemplo, pela proteômica comparativa, onde se identificam proteínas 
expressas diferencialmente de dois ou mais perfis de proteínas em grupos diferentes, sendo eficiente também para identificar os alvos moleculares de drogas e compreender a adaptação a estímulos como o exercício (Burniston et al, 2008). Outra aplicação é o mapa proteômico, utilizado com o intuito de catalogar as proteínas presentes em uma determinada amostra, como o mapa proteômico do envelhecimento humano (Gelfi et al, 2005) e o mapa do envelhecimento em modelo animal (Gelfi et al, 2006).

A metodologia clássica para análise proteômica foi proposta por O'Farrel e Klose em 1975 (Petriz et al, 2012), que consiste na separação e visualização de proteínas através do 2-DE (eletroforese em gel de poliacrilamida bidimensional) e identificação e caracterização molecular de proteínas pelo Espectrômetro de Massas (MS), de forma rápida e precisa, sendo utilizado na identificação de proteínas. Com o avanço tecnológico, outras metodologias de análise foram agregadas ao ramo proteômico. A High Performance Liquid Cromatography (HPLC) ou cromatografia líquida de alta eficiência, é uma técnica de separação de compostos de uma solução, que, acoplada ao MS, fornece melhor desempenho e estrutura para gerar a compreensão de processos biológicos complexos (Gelfi et al, 2006). De forma geral, a técnica consiste na separação de uma solução contendo proteínas previamente digeridas em peptídeos e depois, separados por cromatografia líquida. Após a separação desses compostos, os analitos são ionizados e avaliados de acordo com a razão massa/carga $(\mathrm{m} / \mathrm{z})$ do íon. A fonte de ionização do MS gera íons peptídicos ou proteicos para as moléculas, sem alterar sua estrutura química. Os íons então são acelerados devido a um campo elétrico e separados por $\mathrm{m} / \mathrm{z}$ no analisador de massas ou então, podem ser selecionados de acordo com uma $\mathrm{m} / \mathrm{z}$ previamente determinada, e, posteriormente, fragmentados em um processo denominado tandem (MS/MS) (Figura 1). Quando os íons atingem o detector, este converte o sinal da passagem do íon em sinal identificável. $O$ resultado é apresentado por meio de um gráfico de $\mathrm{m} / \mathrm{z}$ versus intensidade (contagem de íons), comumente referido como espectro MS. Os sinais gerados são comparados com informações disponíveis em bancos de dados como o 
MASCOT, o que permite identificar as proteínas de interesse (May et al, 2011; Barbosa et al, 2012).

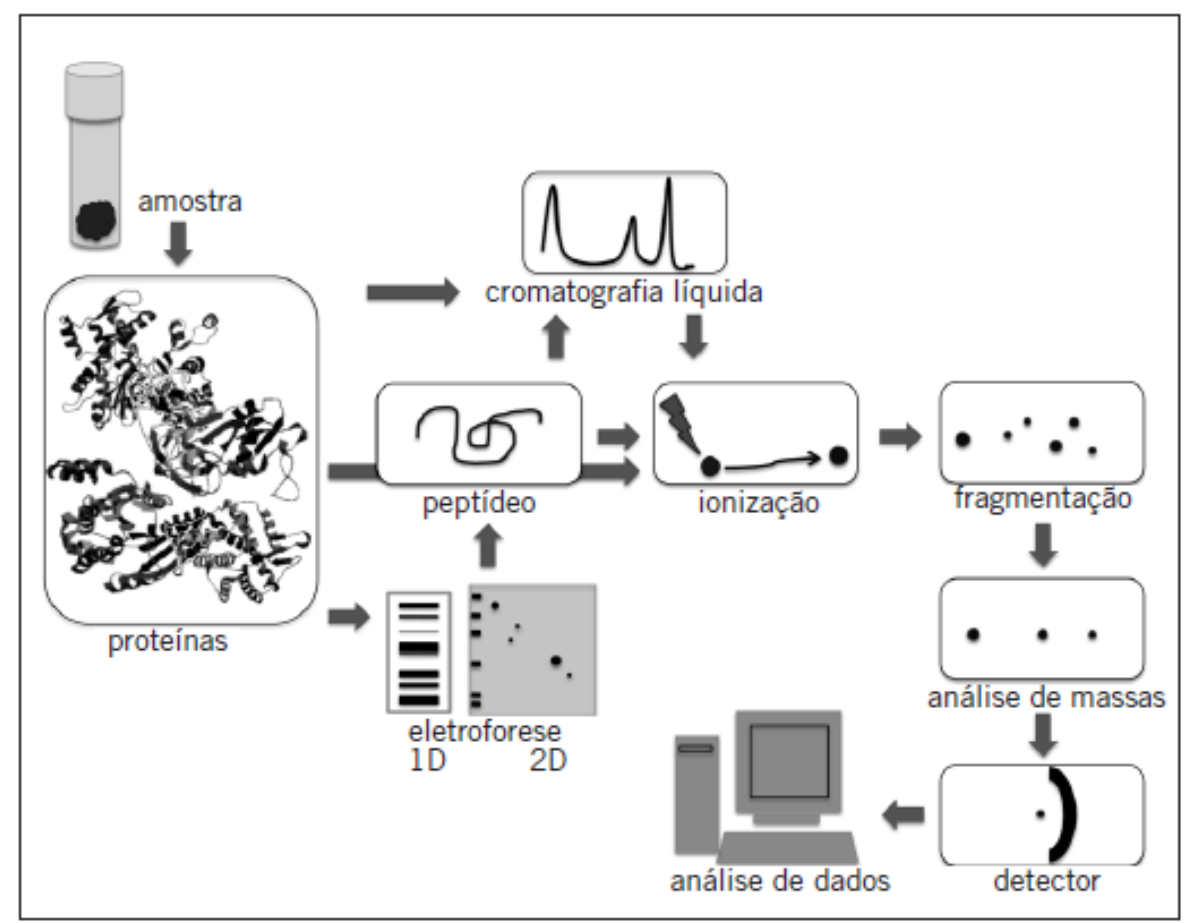

Figura 1. Metodologias que podem ser utilizadas nos estudos proteômicos. Preparação de amostra e digestão para a separação por eletroforese em gel ou por cromatografia líquida, ionização, fragmentação, análise das massas e deteç̧ão para análise de dados (Barbosa et al, 2012).

\subsubsection{Proteômica e envelhecimento}

Frente a essas alterações importantes no processo de senilidade, 0 conhecimento dos processos moleculares que levam à menor capacidade regenerativa do músculo tem sido estudado. A análise proteômica da sarcopenia é tecnicamente desafiadora devido à faixa dinâmica das proteínas expressas nos músculos (Baraibar et al, 2013).

O proteoma do tecido muscular é extensivamente pesquisado e os estudos buscam identificar como o tecido se adapta às condições fisiológicas e patológicas, além da plasticidade muscular frente a ajustes como o exercício, hipóxia e envelhecimento. Grande parte dessas pesquisas analisou o perfil muscular, usando diferentes músculos como o gastrocnêmio, sóleo e vasto lateral, buscando identificar proteínas que 
estejam relacionadas com o processo de envelhecimento, como revisto por Gelfi et al, 2011. O envelhecimento do músculo esquelético tem sido associado à alteração de proteínas contráteis e metabólicas, bem como estados de carbonilação e fosforilação alteradas nesse processo (Piec et al, 2005; Gelfi et al, 2006). Os estudos baseados em espectrometria de massas têm demonstrado transição de fibras rápidas glicolíticas para fibras lentas oxidativas em população de fibras mais velhas (Théron et al, 2014). Esse deslocamento de fibras é constatado pela redução de proteínas como enolase, creatina cinase muscular, aconitase e fosfofrutocinase no músculo (Gannon et al, 2008).

Os aspectos funcionais relacionados à qualidade de contração no músculo velho também tem sido associados às análises proteômicas. Estudo recente realizado por Gregorich et al, 2016 mostraram que os modelos animais de sarcopenia apresentam redução de contração muscular de fibras do tipo II, devido à redução da fosforilação de cadeias leves de miosina. Esse aspecto foi relacionado com a avaliação biomecânica do músculo, demonstrando menor velocidade de encurtamento e diminuição na potência de fibras individuais no músculo velho, pois a desorganização de proteínas contráteis e metabolismo energético no envelhecimento interferem na capacidade de reação e adaptação muscular.

Um grande foco nas análises proteômicas tem sido a análise de estruturas, proteínas e mecanismos isoladas para associação com condições musculares específicas, como redução funcional muscular (Gregorich et al, 2016), modificações pós traducionais, como estados de carbonilação (Feng et al, 2008) e estresse oxidativo (Malconm MCcardle, 2011; Friguet et al, 2015). A análise de frações enriquecidas de mitocôndria, por exemplo, é investigada na tentativa de identificar potenciais biomarcadores para o envelhecimento, pois as disfunções energéticas afetam o sistema neuromuscular e estão diretamente relacionadas com o aumento de EROs (Mcardle et al, 2010; Doria et al, 2012; Stauton et al, 2011). 


\subsubsection{Proteômica e exercício}

Os exercícios físicos são indicados por influenciar na saúde e qualidade de vida do idoso, promovendo alterações intracelulares que favorecem a hipertrofia, aumento de força e resistência (Carvalho et al, 2012; Röckl et al, 2008).

De forma geral, a maioria dos estudos já realizados tem maior foco nas respostas do treinamento de resistência sobre o proteoma e suas modificações no músculo esquelético. Isso pode ser exemplificado pelo trabalho realizado por Lanza et al, 2008 que analisou o efeito do treinamento aeróbio em indivíduos idosos e verificou que a prática de exercício normaliza as disfunções mitocondriais relacionadas à idade, embora não tenha modificado fatores de transcrição nucleares e abundância de proteínas mitocondriais. Além disso, o entendimento das vias de síntese e degradação que modulam o proteoma muscular do envelhecimento frente ao exercício aeróbio, têm sido demonstrado por Fry et al, 2011 e Fry et al, 2013.

Estudos do perfil proteômico após TF possuem metodologias distintas. O estudo de Son et al, 2012, por exemplo, comparou o proteoma do tecido muscular após o treinamento de resistência e o treinamento resistido no músculo vasto lateral de humanos por meio de gel 2-DE após 4 semanas e observou o aumento da abundância de cadeia leve de miosina e redução de piruvato cinase 3 , enolase e albumina após treinamento resistido. A análise do secretoma de células musculares do vasto lateral e trapézio, por meio de q-PCR e western blotting mostrou aumento de colágeno 1, folistatina e gelsolina, além do aumento de seus genes correspondentes após 11 semanas de TR (Nohreim et al, 2011). Outro estudo com treinamento de salto, analisou o músculo plantar após 12 semanas de treino com intervalo de recuperação insuficiente, o que resultou em redução de isoformas de $\mathrm{MHC}$ e de redução de AST e atrofia após o TR (Souza et al, 2011).

As informações relacionadas a proteínas e TR, no perfil do músculo velho, vêm de estudos que analisam as vias que modulam a síntese e degradação de proteínas após exercício. Por meio de análises gênicas e 
western blotting, foi demonstrado que o envelhecimento afeta marcadores para síntese de proteínas em resposta a estímulos anabolizantes e que a ativação do gene da via hipertrófica, alvo de rapamicina em mamiferos (mtorc1) é reduzida em indivíduos velhos em comparação com jovens além de favorecer a restauração das miofibrilas e capacidade para hipertrofia em indivíduos idosos, porém, de forma menos pronunciada quando comparado a jovens (Petrella et al, 2006).

Diante disso, estudos que avaliam o perfil proteômico do músculo velho após o TR ainda precisam ser explorados, pois, demonstradas suas adaptações benéficas no músculo idoso, pode representar uma ferramenta de possíveis aplicações e investigações nessa área. 


\subsection{OBJETIVOS}

O objetivo desse estudo foi analisar e quantificar o nível de abundância de proteínas expressas e a AST do músculo gastrocnêmio após treinamento resistido em animais idosos. 


\subsection{MATERIAL E MÉTODOS}

\subsection{Animais}

Vinte e quatro ratos Wistar (Rattus norvegicus) com 3 meses $(n=12$ / com peso médio de $298,74 \pm 32,32 \mathrm{~g}$ ) e 21 meses ( $n=12$ /com peso médio de $517,83 \pm 76,30 \mathrm{~g}$ ) foram utilizados neste estudo. Os animais foram mantidos sob temperatura constante $\left(22 \pm 2{ }^{\circ} \mathrm{C}\right)$ e ciclo de luz $(12: 12 \mathrm{~h}$ ciclo claro-escuro) com acesso livre a ração padrão e água da torneira. Todos os procedimentos foram realizados de acordo com o Guia Americano para cuidados e uso de animais de laboratório (National Research Council, 1996) e aprovação do Comitê de Ética em Experimentação Animal da Universidade Federal de São Carlos, SP, Brasil (processo: 056/2010 - Anexo I).

\subsection{Grupos experimentais}

Os animais foram divididos aleatoriamente em 4 grupos experimentais (6 animais / grupo), na seguinte ordem: sedentários jovens (SJ); sedentários velhos (SV); treinados jovens (TJ); treinados velhos (TV).

\subsection{Treinamento Resistido}

\subsubsection{Familiarização}

Os ratos foram adaptados a um protocolo de escalada de TR usando uma escada vertical $\left(110 \mathrm{~cm}, 18 \mathrm{~cm}, 2 \mathrm{~cm}\right.$ de grade, $80^{\circ}$ de inclinação), (figura 2), sem peso sobre o aparelho de carga por dois dias não consecutivos (48 horas de descanso entre as escaladas). O aparelho de carga foi fixado à cauda envolvendo a sua porção proximal com uma tira de espuma autoadesiva. $O$ dedo foi usado para beliscar a cauda do animal como um estímulo para iniciar a escalada. Na parte superior da escada, os ratos chegaram a uma câmara de alojamento onde descansaram durante 2 
minutos. Este procedimento foi repetido até que, voluntariamente, os animais pudessem subir a escada por três turnos consecutivos sem estímulo.

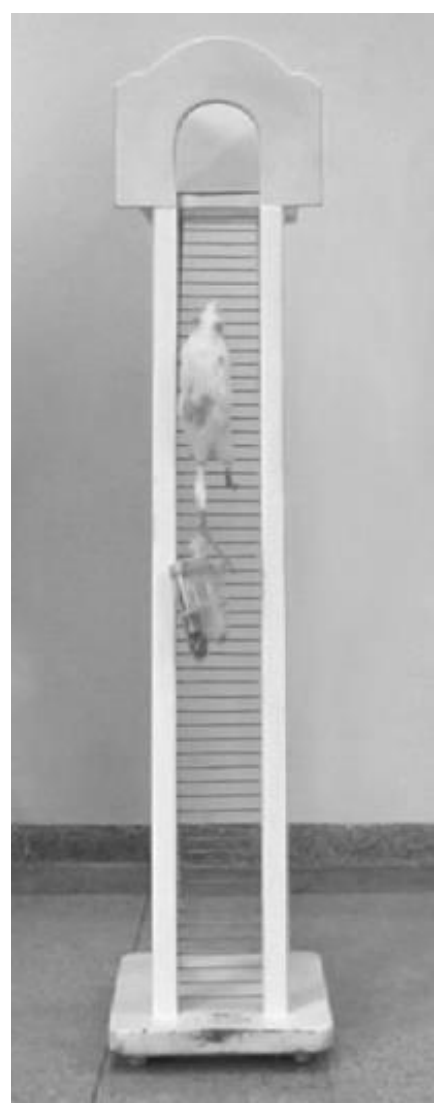

Figura 2. Modelo de escada para o protocolo de treinamento resistido (TR). Foi utilizada uma escada vertical com $110 \mathrm{~cm}, 18 \mathrm{~cm}, 2 \mathrm{~cm}$ de grade e 80 de inclinação com uma câmara de alojamento acoplada ao final da escada. O protocolo de treinamento proposto está de acordo com o estudo de Souza et al, 2014.

\subsubsection{Determinação da capacidade de carga máxima}

Dois dias após o procedimento de familiarização, cada animal foi avaliado para determinar a sua carga máxima, que consistia em 4-9 escaladas com cargas progressivamente mais pesadas. A subida inicial foi realizada com $75 \%$ da massa corporal do animal. Após a conclusão bem sucedida desta carga, um peso adicional de $30 \mathrm{~g}$ foi adicionado para o aparelho de carga. A carga mais elevada que o animal realizava com 
sucesso através de todo o comprimento da escada, foi considerada a capacidade de carga máxima do rato para a sessão de treino. A falha foi determinada quando o animal não pode progredir até a escada depois de três estímulos sucessivos na cauda.

\subsubsection{Período de treinamento resistido}

O TR foi realizado em dias alternados, três vezes por semana (segundas, quartas e sextas-feiras), durante 12 semanas. O comprimento da escada permitiu que os animais fizessem 8-12 movimentos dinâmicos por subida. As subidas consistiam em transportar uma carga progressiva de 65, 85,95 e 100\% da capacidade de carga máxima de cada animal. As sessões de TR consistiram de 5-8 escaladas. Se um rato atingiu $100 \%$ de sua capacidade de carga, foi adicionada uma carga adicional de $30 \mathrm{~g}$ até que foi determinada uma nova capacidade de carga máxima. O período de descanso entre cada subida foi de 2 minutos. $O$ protocolo de treinamento resistido utilizado está de acordo com Souza et al, 2014.

\subsubsection{Coleta do músculo e avaliação da área de secção transversa}

Quarenta e oito horas após a última sessão de treino, os animais foram anestesiados com uma injeção intraperitoneal com uma solução de Xilazina (12 mg / kg de peso corporal) e sacrificados utilizando Ketamina (95 $\mathrm{mg} / \mathrm{kg}$ de peso corporal) e pesados. Em seguida, os músculos gastrocnêmio foram cuidadosamente removidos, pesados e em seguida, divididos em duas partes no ventre muscular: o fragmento proximal foi utilizado para a análise de AST e a distal para a avaliação proteômica. Para a avaliação da AST, o fragmento de músculo foi imediatamente congelado em isopentano e armazenado num congelador a $-80^{\circ} \mathrm{C}$ (Forma Scientific, Marietta, Ohio). Os Cortes histológicos (10 uM) do ventre de cada músculo gastrocnêmio foram obtidos em criostato (Micron HE 505, Jena, Alemanha), coradas com azul de Toluidina a $1 \%$ e analisados por microscopia de luz (Axiolab, Carl Zeiss, Jena, Alemanha). A AST de 100 fibras escolhidas 
aleatoriamente de cada imagem foi medida utilizando o software Axiovision 3.0.6 SP4 (Carl Zeiss, Jena, Alemanha), totalizando 600 fibras musculares por animal como utilizado por Durigan et al, 2014.

\subsection{Extração e quantificação de proteínas}

Os músculos congelados foram macerados em nitrogênio líquido e mecanicamente homogeneizados com uma solução de lise (ácido cacodílico $10 \mathrm{mM}, 1 \mathrm{uM}$ de NaCl, $\mathrm{CaCl}_{2} 20 \mathrm{mM}, \mathrm{NaN}_{3}$ 1,5 mM, 0,01\% de Triton X-100\% $\mathrm{ZnCl} 1 \mathrm{uM}$ e CIP (coquetel inibidor de protease). Para quantificação de proteínas, foi utilizado o método de fluorescência PierceBCA Kit de ensaio de proteína $(B C A)$. Após esta fase, as amostras foram tratadas para remover Triton-X100 conforme o protocolo utilizado pela Yeung e Stanley, 2010. Depois, foi adicionado bicarbonato de amônia $50 \mathrm{mM}$, até completa homogeneização da amostra. Em seguida, foram incubadas durante a noite na geladeira a $4^{\circ} \mathrm{C}$. Subsequentemente, a amostra foi centrifugada durante 30 min a $14,000 \times$ g. O sobrenadante foi removido e testado por Qubit $\AA$ e as amostras foram digeridas com tripsina.

\subsubsection{Preparação da amostra para a aquisição por LC-ESI-MS/MS}

Para a digestão de proteínas, foi adicionado a cada amostra, 20 uL de $\mathrm{NH}_{4} \mathrm{HCO}_{2} 50 \mathrm{mM}$ (Vetec) e 50 ul de solução de RapiGest тM (Waters, Milford, MA, EUA) e incubou-se a $80^{\circ} \mathrm{C}$ durante 15 min e posteriormente centrifugadas durante $15 \mathrm{seg}$ (spin). Subsequentemente, foram adicionados 5 ul de DTT (dietiotreitol) $100 \mathrm{mM}$ (GE Healthcare) e, em seguida, a amostra foi agitada e incubada a $60^{\circ} \mathrm{C}$ durante $30 \mathrm{~min}$. Após o período de incubação, as amostras foram deixadas para resfriamento até à temperatura ambiente $\mathrm{e}$ centrifugadas durante $15 \mathrm{seg}$. Subsequentemente, foram adicionadas $5 \mu \mathrm{L}$ de $300 \mathrm{mM}$ de IOD (iodoacetamida) (GE Healthcare), agitados e incubados durante $30 \mathrm{~min}$ à temperatura ambiente e protegida da luz. Em seguida, adicionou-se $40 \mu \mathrm{l}$ de solução de tripsina (Promega Corporation, Brasil) em $\mathrm{NH}_{4} \mathrm{HCO}_{2} 50 \mathrm{mM}$ (Vetec) a uma proporção de 1:1000. As amostras foram 
novamente agitadas e incubadas a $37^{\circ} \mathrm{C}$ durante $18 \mathrm{~h}$ para a digestão. Após digestão, foram adicionados $20 \mu \mathrm{l}$ de ácido trifluoroacético (TFA), 5\% (Mallinckrodt Pharmaceuticals, Dublin, Irlanda), agitadas e as amostras incubadas a $37^{\circ} \mathrm{C}$ durante $90 \mathrm{~min}$. Em seguida, foram centrifugados a $14,000 \times \mathrm{g}, 6^{\circ} \mathrm{C}$ durante $30 \mathrm{~min}$. O sobrenadante foi transferido para um tubo de microcentrífuga $(1,5 \mathrm{ml})$ e evaporada em um liofilizar (LIOTOP). Finalmente, as amostras foram ressuspendidas em ácido fórmico a 0,1\% em água grau LC-MS, misturada, centrifugada durante $5 \mathrm{~min}$ a $14,000 \mathrm{x}$ g e 0 sobrenadante removido e utilizado para análise.

\subsubsection{Aquisição e processamento de dados por LC-ESI-MS / MS}

Os experimentos de LC-ESI-MS/MS foram realizados em um cromatógrafo líquido de alta eficiência ou Liquid cromatography (LC) do tipo fast, (Shimadzu, Kyoto, Japão), acoplado a um espectrômetro de massas do tipo ESI micrOTOF-Q III (BrukerDaltonics, Alemanha). A separação dos peptídeos foi realizada, fazendo uso de uma coluna XR-ODS C18 $2.0 \mathrm{~mm} 26$ x $30 \mathrm{~mm}$ x $2.2 \mu \mathrm{m}$ (Kyoto, Japão), tendo como solventes, 0,1\% de ácido fórmico em água e acetonitrila $100 \%$, acrescida de $0,1 \%$ de ácido fórmico como fases móveis, A e B, respectivamente. Utilizando um gradiente de $5 \%$ de B por $5 \mathrm{~min} ; 5-50 \%$ de B por $50 \mathrm{~min} ; 50-95 \%$ de B por $10 \mathrm{~min} ; 95 \%$ de B por $8 \mathrm{~min}$; $95-5 \%$ de B por $1 \mathrm{~min}$ e $5 \%$ de B por $7 \mathrm{~min}$, totalizando $80 \mathrm{~min}$, sob um fluxo de $400 \mu \mathrm{L}$.min-1. As análises de ESI foram realizadas sob modo linear positivo, nos seguintes parâmetros: spray voltage, $4.5 \mathrm{kV}$, utilizando nitrogênio $\left(\mathrm{N}_{2}\right)$ como fonte de ionização, nebulizer 4.0 Bar, drygas 8.0 , drytemp $200^{\circ} \mathrm{C}$. Os íons foram escaneados sob um intervalo de 300 $3.000 \mathrm{~m} / \mathrm{z}$, seguido de cinco MS/MS scans. Os dados brutos de fragmentação (MS/MS), gerados pelo equipamento, foram analisados por meio do programa Data Analysis (Bruker Daltonics, Alemanha), em que foram separados todos os íons que foram fragmentados de acordo com os parâmetros citados acima, através da ferramenta AutoMs(n); na sequência, os espectros foram "deconvoluídos" por meio da ferramenta Deconvolute para, então, determinar o estado de carga de peptídeo gerado após 
fragmentação. Os dados foram importados para o progama BioTools (Bruker Daltonics, Alemanha) onde foram realizadas as buscas, utilizando 0 algoritmo MASCOT (Matrix Science, London, United Kingdom, versão 2.3). O banco de dados utilizado foi o UniProt, SwissProt, (Switzeland, Geneva), sendo as buscas direcionadas para a taxonomia Rattus (546.439 sequências e 194.445.396 resíduos). A Tripsina foi selecionada como enzima de clivagem, seguida das possíveis modificações: carbamidometilação da cisteína $\left(C^{*}\right)$, como modificação fixa e oxidação de metionina (Mox), determinada como modificação variável. Como critério de inclusão, a tolerância de massas para os íons precursores (MS) e para os fragmentos de íons (MS/MS) foi de $\pm 0.2 \mathrm{Da}$. As proteínas foram consideradas "identificadas", quando o escore dos peptídeos foi maior que o escore mínimo para o limite de confiança de $95 \%(p<0.05)$, que por sua vez, foi obtido por meio do match de cada peptídeo gerado em relação ao seu perfil de fragmentação teórico. Além disso, todos os íons deveriam estar presentes nas triplicatas realizadas.

\subsubsection{Quantificação de proteínas por LC-MS}

As proteínas comuns em todos os grupos experimentais foram quantificadas com o objetivo de estudar o perfil de expressão entre os diferentes grupos, por meio da ferramenta Data Analysis. A presença das proteínas, para quantificação, era necessária em todas as triplicatas realizadas de cada animal, e eram calculadas por meio da área do pico dos íons encontrados. Os íons foram extraídos por meio da ferramenta extracted chromatogram (XICs), que estavam relacionados com a proteína identificada. A área de cada íon foi calculada com o auxílio da ferramenta Integrate only Chromatogram, sendo esses valores utilizados para os cálculos de intensidade e posterior comparação com os demais grupos. Como critério de inclusão, foram quantificadas as proteínas presentes em todos os grupos. 


\subsection{Análise estatística}

A normalidade dos dados foi testada utilizando o teste de ShapiroWilk e Levene $(p>0,05)$ e os dados apresentados por meio de histograma, considerando a média e o desvio padrão. Como as variáveis foram distribuídas normalmente, um ANOVA de duas vias (treinamento e idade) seguido de um teste post hoc de Tukey HSD foram realizadas para comparar tratamentos. As diferenças foram consideradas significativas quando $p<0,05$. A análise estatística foi realizada utilizando o pacote de software Statistica 7.0. (Stat Soft Inc., Tulsa, OK, EUA). 


\subsection{RESULTADOS}

\subsection{Capacidade de carregamento máximo}

A capacidade de carregamento relativo dos animais aumentou em ambos os grupos treinados (TJ e TV). No grupo TJ, após a segunda semana, houve aumento de 21,3\% comparada á semana inicial. Na sexta semana de treinamento, aumentou $19,7 \%$, comparada à segunda semana. $\mathrm{A}$ partir da sétima semana, a carga se manteve estável até a 12ª semana de treinamento. Já o grupo SV aumentou a carga a partir da quarta semana $(33,6 \%)$, quando comparada a inicial, mantendo-se estável até o final do treinamento (semana 12).

\subsection{Dados Qualitativos LC-ESI-MS/MS}

Os dados analisados neste trabalho mostraram a presença de 131 proteínas identificadas pelo LC-ESI-MS/MS. Dessas 131 proteínas totais identificadas, 48 seguiram os critérios de inclusão (ver tópico 4.4.2) e foram classificadas de acordo com a base de dados Uniprot e Panther, sendo separados em processo biológico, função molecular e compartimento celular. A maioria das proteínas reguladas relacionadas ao processo biológico é associada ao processo metabólico (40\%), seguido por localização (11\%), regulação biológica (7\%), processo apoptótico $(7 \%)$, processo celular (4\%) e desenvolvimento de processos (4\%), como ilustrado na figura 3A. A principal atividade observada em relação a função molecular foi atividade catalítica (32\%), seguida por ligação (15\%), atividade antioxidante $(6 \%)$, oxiredutase/transferase $(6 \%)$ e cinase/transferase $(6 \%)$ ilustrado pela figura 3B. Além disso, o principal componente celular encontrado foi o citoplasma (52\%), processos não preditos (15\%), seguidos por mitocôndria (9\%) e secretados (7\%), figura 3C. 

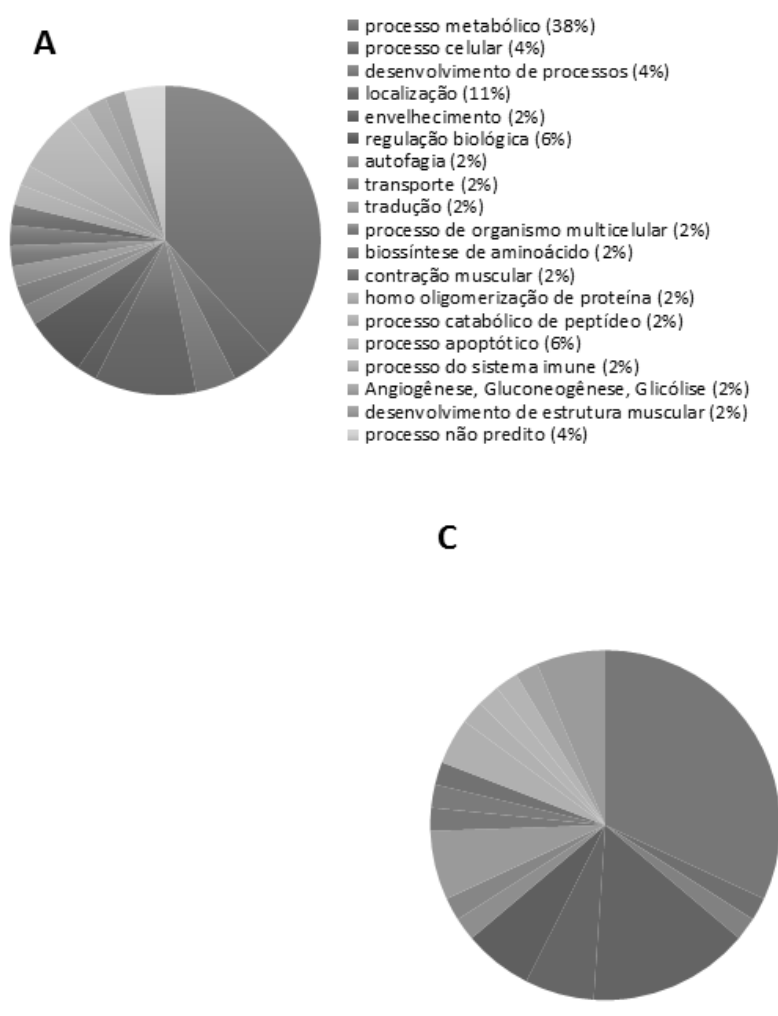

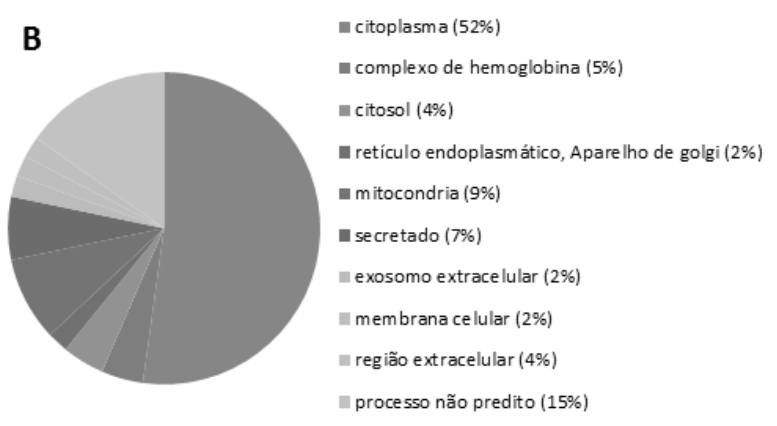

atividade catalítica ( $32 \%)$

atividade de transporte de oxigênio (2\%)

In cinase, transferase $(2 \%)$

- ligação (15\%)

I atividade antioxidante $(6 \%)$

I oxidoredutase/transferase $(6 \%)$

atividade de receptor $(2 \%)$

- hidrolase, Isomerase $(2 \%)$

- proteína muscular $(6 \%)$

citocina, fator de crescimento, isomerase $(2 \%)$

II chape rona, hidrolase, protease $(2 \%)$

- inibidor de protease, inibidor de protease de serina $(2 \%)$

- ligação de antígeno (4\%)

II am inotransferase, transferase $(2 \%)$

(1I) receptor de benzodiaze pina de ligação $(2 \%)$

II am inopeptidase, hidrolase, prote ase $(2 \%)$

(1) ribonucleoprote ina, proteina ribossomal $(2 \%)$

|| processo não predito (6\%)

Figura 3. Proteínas classificadas de acordo com o processo biológico (A), função molecular (B) e componente celular (C) de acordo com as bases de dados Uniprot e Panter.

Entre as 48 proteínas reguladas, 28 foram comuns a todos os grupos. Porém, somente 24 foram quantificadas, pois 4 proteínas não estavam presentes em todas as triplicatas. Além disso, 6 proteínas reguladas foram exclusivas, com 2 no grupo SJ (fator de liberação de cadeia peptídica 1, mitocondrial (RF1ML) e colágeno alfa 1 (COL1A1), 1 exclusiva do grupo TV (ubiquitina-40s proteina ribosomal S27a (RS27A), 3 exclusivas do grupo SV (peroxiredoxina 6 (PRDX6), serotransferrina (TRFE) e miosina-4 (MYH4), sendo que nenhuma proteína foi exclusiva no grupo TJ (Figura 4). 


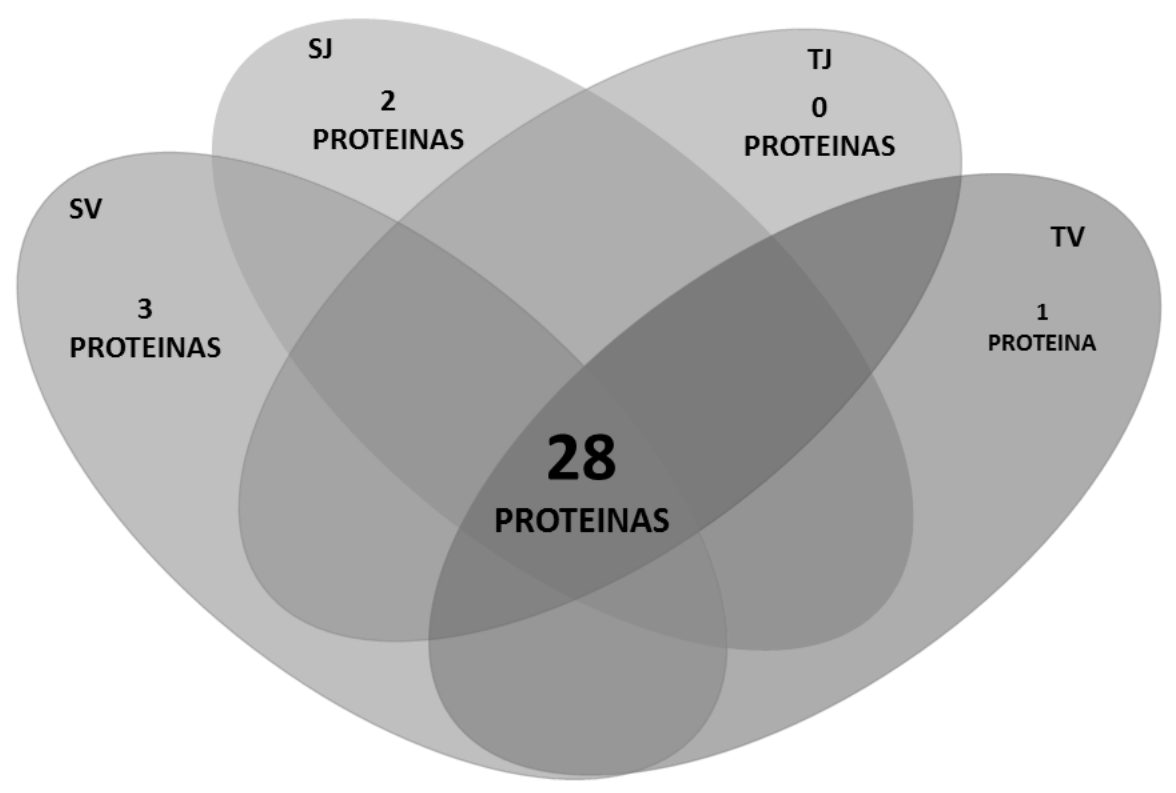

Figura 4. Proteínas comuns e exclusivas reguladas entre os grupos, sedentário jovem (SJ), treinado jovem (TJ), sedentário velho (SV) e treinado velho (TV).

\subsection{Abundância de Proteínas no envelhecimento}

A quantificação e análise foram feitas em 24 proteínas comuns a todos os quatro grupos. A análise estatística mostrou que o envelhecimento aumentou ( $p<0,05$ / Apêndice I) a abundância de 18 proteínas (Figura $5 A$ ), quando comparamos os grupos não exercitados (SJ $\times$ SV), sendo 9 aumentadas, principalmente relacionadas ao processo metabólico, como a fosfoglicerato cinase 1 (PGK1), creatina cinase tipo M (KCRM), glicose-6fosfato isomerase (G6PI), gliceraldeído-3-fosfato dehidrogenase (G3P) betaenolase (ENOB), triosefosfato isomerase (TPIS), fosfoglicerato mutase 2 (PGAM2) fosfoglucomutase 1 (PGM1) e L-lactato dehidrogenase cadeia $A$ (LDHA); 2 proteínas estruturais aumentadas, cadeia leve de miosina 2 (MLRS) e cadeia leve de miosina 1/3 (MYL1); 3 proteínas antioxidantes aumentadas, superóxido dismutase $\mathrm{Cu}-\mathrm{Zn}$ (SODC), peroxiredoxina 1 (PRDX1) e proteína deglicase DJ 1 (PARK7), além de 4 proteínas de transporte, hemoglobina subunidade alfa-1/2 (HBA) hemoglobina subunidade beta 1 (HBB1), anidrase carbônica $3\left(\mathrm{CAH}_{3}\right)$ e mioglobina (MYG). 


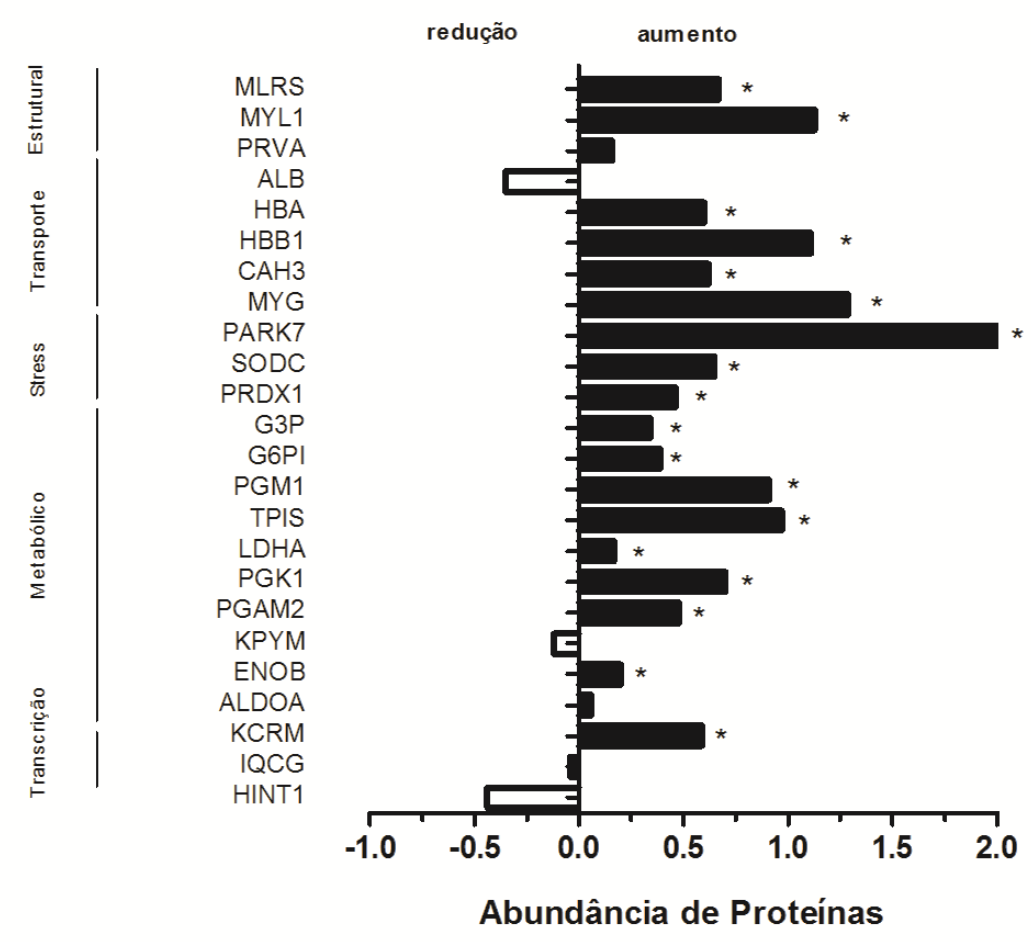

Figura 5A. Efeito do envelhecimento no perfil proteômico do músculo gastrocnêmio. Histograma das proteínas entre o grupo controle sedentário jovem (SJ) e o grupo sedentário velho (SV), classificados em Estruturais, Transporte, Estresse, Metabólicas e Transcrição. $O$ eixo x representa a razão de Log (e) entre os grupos. Redução na abundância das proteínas é representada em escala negativa (barra branca) à esquerda e o aumento da abundância de proteínas, em escala positiva (barra preta) à direita do eixo y. * indica significância de $p>0.05$.

\subsubsection{Abundância de Proteínas após Treinamento resistido}

O TR aumentou ( $p<0.05 /$ Apêndice II) a abundância de 20 proteínas (Figura 5B) quando comparamos os grupos SJ x TJ, e assim como no envelhecimento, todas foram aumentadas, sendo 11 relacionadas principalmente ao processo metabólico, como PGK1, frutose-bisfosfato aldolase A (ALDOA), KCRM, piruvato quinase (KPYM), G3P, G6PI, ENOB, PGAM2, TPIS, LDHA, PGM1; 2 proteinas antioxidantes aumentadas, SODC, PARK7; 3 proteínas estruturais aumentadas, parvalbumina alfa (PRVA), 
MYL1 e MLRS e 4 proteínas de transporte aumentadas, HBA, $\mathrm{HBB} 1, \mathrm{CAH}_{3}$ e MYG .

$5 B$

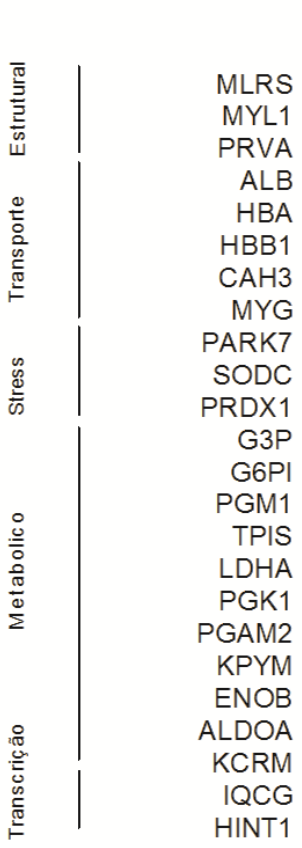

SJ vs TJ

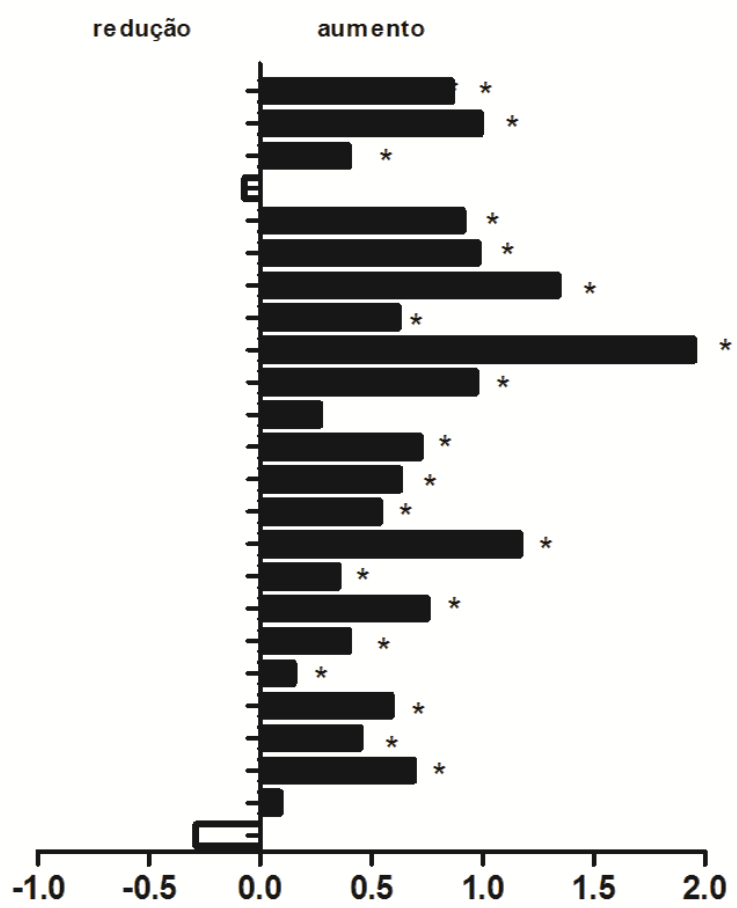

Abundância de Proteínas

Figura 5B. Efeito do treinamento resistido no perfil proteômico do músculo gastrocnêmio jovem. Histograma de proteínas entre o grupo controle sedentário jovem (SJ) e o grupo treinado jovem (TJ), classificado em proteínas Estruturais, Transporte, Estresse, Metabólicas e Transcrição. O eixo x representa a razão de Log(e) entre os grupos. A redução na abundância das proteínas é representada em escala negativa (barra branca) à esquerda e o aumento da abundância de proteínas, em escala positiva (barra preta) à direita do eixo y. * indica significância de $p>0.05$.

6.3.2 Abundância de Proteínas no músculo velho após Treinamento resistido

O TR aumentou a abundância de 8 proteínas ( $p<0.05 /$ Apêndice III) e reduziu 5 proteínas $(p>0.05$ ) (Figura $5 C$ ) quando comparamos $S V \times$ TV. Seis proteínas estão relacionadas principalmente ao processo metabólico, com cinco aumentadas, ALDOA, KPYM, G3P, G6PI, ENOB e uma reduzida, 
PGM1. Duas proteínas relacionadas ao processo antioxidante, sendo SODC aumentada e PRDX1 reduzida e 1 proteína estrutural reduzida, MYL1. Quatro proteínas transportadoras também foram expressas, sendo 2 aumentadas, $\mathrm{CAH}_{3}$ e HBA e 2 reduzidas, MYG e HBB1. A proteína de ligação tríade histidina (HINT1) mostrou aumento somente no grupo TV comparada ao SJ. Além disso, a análise das proteínas albumina (ALB) e proteína G domínio IQ (IQCG) não mostraram diferença estatística entre os grupos analisados $(p>0.05)$.

$5 \mathrm{C}$ SV vs TV
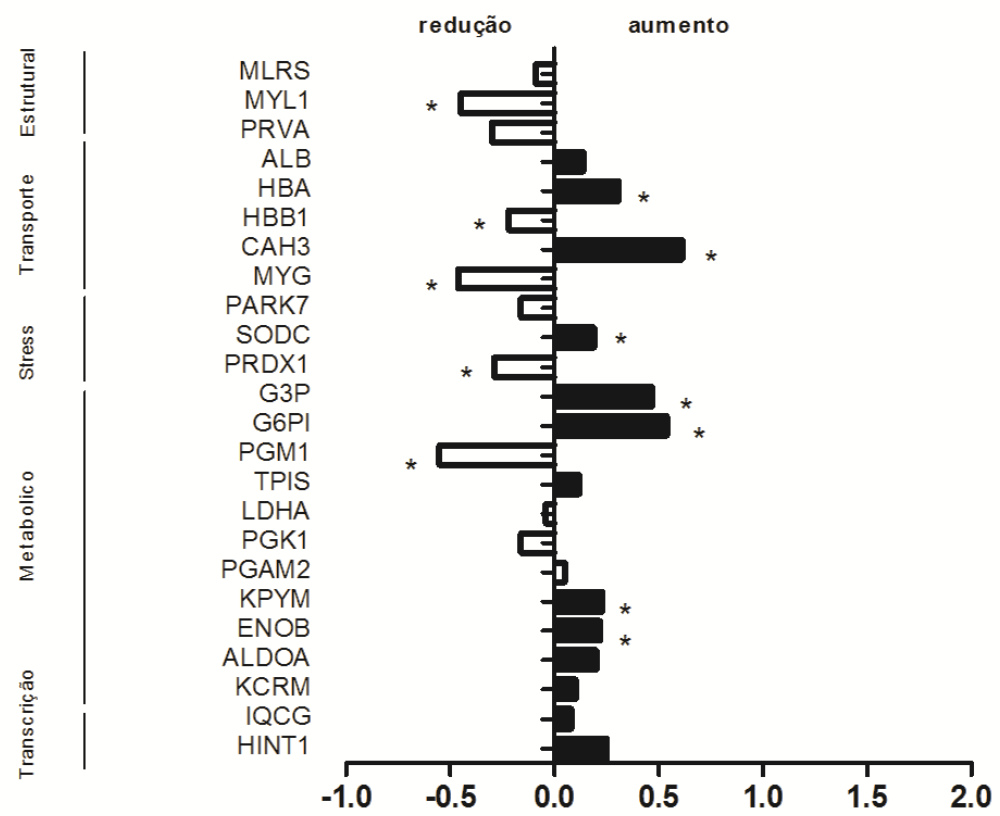

Abundância de Proteínas

Figura 5C. Efeito do treinamento resistido no perfil proteômico do músculo gastrocnêmio velho. Histograma das proteínas entre o grupo sedentário velho (SV) e treinado velho (TV), classificados em proteínas Estruturais, Transporte, Estresse, Metabólicas e Transcrição. O eixo x representa a razão de $\log (\mathrm{e})$ entre os grupos. Redução na abundancia das proteínas é representado em escala negativa (barra branca) à esquerda e o aumento da abundância de proteínas, em escala positiva (barra preta) à direita do eixo y. ${ }^{*}$ indica significância de $p>0.05$. 


\section{4 Área de secção Transversa (AST)}

A AST do músculo gastrocnêmio foi mensurada pela distribuição e porcentagem total de fibras (\%) como ilustrado na figura 6. Os grupos treinados apresentaram efeitos positivos com maior porcentagem de fibras. O grupo TJ apresentou valores $>40 \%$ com distribuição entre 2501 - >3000 $\mu \mathrm{m}^{2}$. E o grupo SJ apresentou valores $>80 \%$, com distribuição entre $2501-$ $>3000 \mu \mathrm{m}^{2}$. O grupo SV mostrou valores $>80 \%$ com distribuição de fibras entre $1001-2000 \mu \mathrm{m}^{2}$, enquanto o grupo TV apresentou o mesmo número de fibras observadas, porém, com distribuição entre $1501-2500 \mu \mathrm{m}^{2}$.
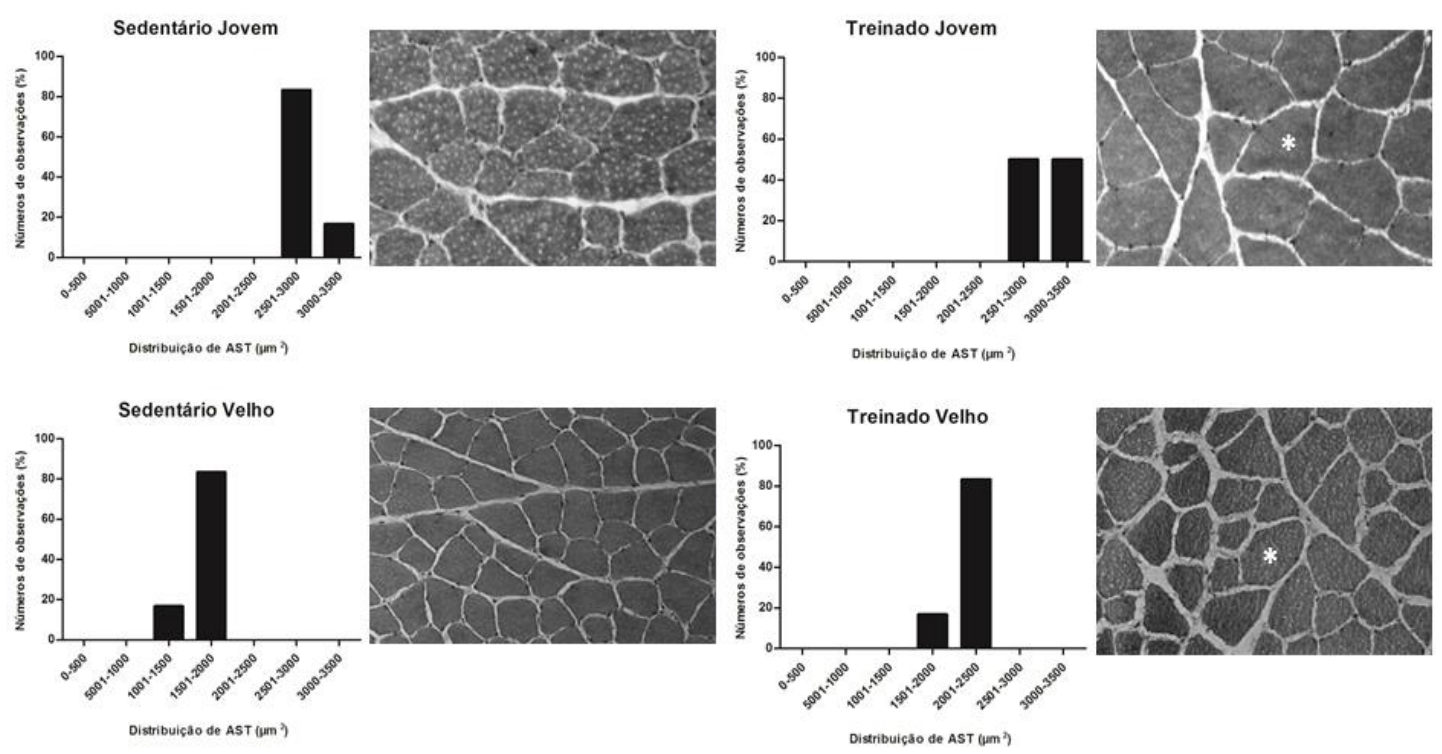

Figura 6 - Área de secção transversa (AST) apresentadas em distribuição $\left(\mu \mathrm{m}^{2}\right)$ e número de observações (\%) do músculo gastrocnêmio nos grupos sedentário jovem (SJ), treinado jovem (TJ), sedentário velho (SV) e treinado velho (TV). Aumento da AST (asterisco branco) nos grupos treinado jovem e treinado velho em comparação aos controles sedentários jovens e sedentários velhos (barra de escala, $50 \mu \mathrm{m}$ ). 


\subsection{DISCUSSÃo}

O presente estudo identificou o perfil proteômico de animais velhos após o TR. O processo de envelhecimento promoveu aumento de proteínas relacionadas à via glicolítica, proteínas do sarcômero, antioxidantes e de transporte e remoção de oxigênio, o que pode ser associado a menor capacidade de adaptação do tecido velho. O TR no grupo velho (Grupo TV) apresentou redução de proteínas sarcoméricas, vias glicolíticas e de transporte de oxigênio, o que pode ser associado à menor responsividade do músculo velho ao estímulo do exercício, apesar da AST ter sido aumentada nesse mesmo grupo.

Nossos resultados apresentaram aumento da AST em ambos os grupos treinados, com aumento significativo do grupo TV quando comparado ao seu controle SV. A análise de AST, o SV obteve a menor distribuição de fibras (1001-1500 $\mathrm{m}^{2}$ ), confirmando estudos que mostram tanto em modelo animal quanto em biópsia de humanos idosos, uma redução significativa de cerca de $40 \%$ da AST no membro inferior, especialmente em fibras tipo II (Ballak et al, 2014; Marzetti et al, 2013; Nilwilk et al, 2013).

Em relação às proteínas estruturais, foi observado aumento de MLRS, MYL1 no envelhecimento e treinamento, porém, redução de MYL1 no grupo TV. A miosina é um hexâmetro composto por duas cadeias pesadas, duas cadeias leves de regulação (RLC) e duas cadeias leves essenciais, que em conjunto, fornecem velocidade de contração (Gelfi et al, 2011). Seus níveis alterados promovem modificações neurais e motoras que refletem no tipo, tamanho e menor recrutamento de fibras musculares (Gelfi et al, 2012). Com o avanço da idade, a faixa dinâmica de proteínas de cadeias leves é aumentada ou reduzida como consequência da transição de metabolismos das fibras para um metabolismo mais oxidativo, o que leva o tecido á reduzir sua capacidade de contração muscular e prejuízo do mecanismo de adaptação a cargas (Gannon et al, 2008; Gannon et al, 2012; Théron et al, 2014). Ainda assim, nós encontramos aumento das isoformas de cadeias leves de miosina e PRVA em ratos jovens após o TR. A PRVA participa do processo de contração-relaxamento das fibras rápidas e atua sobre a 
cinética de $\mathrm{Ca}+$ (Lynch et ai, 2012), o que também pode ser associado ao aumento de AST nos grupos treinados (figura 5). Nossos resultados confirmam o aumento de cadeia leve de miosina já mostrada em estudos prévios (Gelfi et al, 2006; Norheim et al, 2011; Son et al, 2012). A redução de MYL1 no grupo TV pode ser relacionada com a menor capacidade de adaptação do músculo velho ao exercício, pois, têm sido demonstrado que indivíduos idosos que realizaram TR tem menor sensibilidade ao uso de aminoácidos e menor capacidade de síntese miofibrilar, o que reduz a fosforilação de genes importantes para a via hipertrófica (via mTOR p70S6K) no músculo velho (Cuthbertson et al, 2005 e Kumar et al, 2009). Essa condição não foi observada no grupo $\mathrm{TJ}$, o que mostra um possível caminho para o entendimento do processo envelhecimento-exercício.

Nós também observamos aumento das proteínas de transporte HBA, HBB1, MYG, $\mathrm{CAH}_{3}$ no envelhecimento e treinamento, porém, redução de HBB1, MYG após TR em animais velhos. A proteína MYG, é uma proteína conhecida por ser um biomarcador do processo de transição de fibras (Gelfi et al, 2005) decorrentes de desordens na microcirculação de fibras musculares durante o envelhecimento humano (Bearden, 2006; Stauton et al, 2012). Um aumento da demanda para a remoção de CO2 no músculo idosos por meio da proteína $\mathrm{CAH}_{3}$ (Staunton et al, 2012) e maior eficiência do transporte de oxigênio realizado pela presença $\mathrm{MB}$, sugere aumento do metabolismo oxidativo nas fibras musculares de animais velhos (O'Connell et al, 2009; Doran et al, 2008). Porém, o aumento de MYG, $\mathrm{CAH}_{3}$ e isoformas de hemoglobina após o treinamento indicar os efeitos vasculares decorrentes do treinamento de força como demonstrado por Sietsema et al, 2012. A redução de MYG e HBB1 no grupo TV pode ser relacionada a redução do processo de transição de fibras após do TR, já que o aumento de MYG é conhecido por ser um biomarcador do processo de transição de fibras (Gelfi et al, 2005).

Interessantemente, as proteínas de estresse SODC, PRDX1, PARK7 também se mostraram aumentadas no envelhecimento. A proteína PRDX1 foi reduzida no grupo TV e SODC aumentada. A produção de peróxido de hidrogênio $\left(\mathrm{H}_{2} \mathrm{O}_{2}\right)$ e espécies reativas de oxigênio (EROs) são resultados 
fisiológicos da respiração mitocondrial, porém, disfunções nessa organela aumentam a produção dessas espécies, com maior produção durante 0 envelhecimento, o que gera danos a proteínas e alteração da síntese de ATP (Doria et al, 2012). Gueugneau et al, 2014 mostraram o aumento de síntese de proteínas antioxidantes e modificações na homeostase iônica no envelhecimento devido a essas proteínas. Sietsema et al, 2012, demonstraram que o exercício excêntrico aumenta a circulação de isoformas de hemoglobina devido à hemólise, resultante do dano muscular provocado pelo exercício excêntrico, o que pode explicar o aumento das proteínas de transporte neste estudo. Além disso, Gandra et al, 2012 observaram que a proteína SODC mitocondrial foi aumentada no músculo gastrocnêmio vermelho de ratos após treinamento de alta intensidade em esteira, resultando em aumento da capacidade antioxidante, assim como demonstrado em nosso estudo, que apresentou aumento significativo nas proteínas antioxidantes SODC e PARK7. Estudos anteriores mostram que SODC participa da defesa das células contra ERO e as peroxiredoxinas, principalmente PDRX1 pode atuar como mediador inflamatório na imunidade e reparação de tecidos in vivo (Ishi et al, 2012). A PDRX1 é da família das chaperonas e também tem importância na manutenção da integridade celular e remodelação induzida pela idade. A proteína PARK7 tem várias funções, mas já está estabelecido que também participa da resposta ao estresse oxidativo mitocondrial (Ishi et al, 2012). Embora existam resultados conflitantes na literatura, os altos níveis dessas proteínas no músculo de idade podem ser relacionados ao fato de que o processo de envelhecimento favorece a sinalização da proteína PARK7, bem como a proteína SODC contra as EROs (Sakellariou et al, 2011). Estudos tem mostrado alteração da microvasculatura durante o processo de envelhecimento, porém, o exercício pode contrabalancear esses efeitos, promovendo aumento da bioenergética muscular e minimizando as alterações vasculares, preservando o endotélio (Burniston et al, 2014). Por outro lado, a proteína de estresse SODC aumentou e a proteína PRDX1 reduziu no grupo TV comparada ao SJ. Possivelmente, O TR pode ter balanceado a produção e remoção de EROS no músculo velho. Ainda assim, Radák et al, 2002, demonstrou redução de 
produtos de danos de DNA por meio de western blotting, sugerindo que o TR pode aumentar o reparo do DNA e a resistência do músculo idoso aos danos advindo do estresse oxidativo

Relacionado ao envelhecimento e TR sobre as proteínas metabólicas, nossos resultados mostraram aumento das proteínas PGK1, G6PI, KCRM, G3P, ENOB, TPIS, PGM1, PGAM2, LDHA com o envelhecimento e treinamento, porém, redução de PGM1 no grupo TV. Essas proteínas apresentadas na via glicolítica são enzimas chaves na conversão dos substratos na via de glicólise, assim como na produção de ATP. O aumento das proteínas metabólicas é associado ao aumento do mecanismo de contração, uma vez que são responsáveis pela rápida conversão de fosfato de creatina para produção de ATP (Ohlendieck, 2010) e aumento do consumo de energia, principalmente durante atividades de alta intensidade (LeBrasseur et al, 2011). A PGM1 é uma proteína metabólica e possui papel chave na via glicolítica. Porém, ela também está envolvida em outras vias como a via do glicogênio e gluconeogênese, importantes para a síntese de proteínas relacionadas com o exercício resistido. Em consonância, o PGM1 realiza a conversão de glucose-1-fosfato para glicose-6-fosfato a partir de um substrato de glicogênio e favorece rápida produção de ATP. Em constraste, isso ocorre lentamente, pelo processo natural do envelhecimento, o que reduz a atividade da proteína, mesmo com o estímulo do TR.

Em relação às proteínas exclusivas, apenas três foram encontradas no grupo SV, sendo relaciondas ao processo de oxidação celular (PRDX6), sarcômeros (MYH4) e transporte (TRFE). No envelhecimento, os níveis reduzidos de ingestão de ferro e alterações de proteínas antioxidantes aumentam a suscetibilidade do músculo ao estresse oxidativo, prejudicando a manutenção da integridade estrutural muscular e neural (Nyström et al, 2012; Han, Kim, 2015). Esses diferentes resultados no perfil do músculo velho podem ser consequência dos ciclos de degeneração-regeneração, o que leva a diferentes abundâncias no conteúdo proteico, sugerindo alterações na circulação e metabolismo no envelhecimento (Doran et al, 2008; Ibebunjo et al, 2012). Além disso, duas proteínas foram exclusivas no 
grupo SJ, entre elas a proteína de transcrição RF1ML e a proteína de colágeno COL1A1, sugerindo um aumento do processo fibroso, assim como a desidratação dos componentes da matriz que podem aumentar as ligações cruzadas de colágeno, como previamente descrito (Ibebunjo et al, 2012; Kjaer, 2004) e possível redução da biogênese mitocondrial pela redução da proteína RF1ML (Sun et al, 2011).Somente uma proteína, RS27A, no grupo TV mostrou - se dependente do estímulo do TR. Essa proteína participa do processo de ubiquitinação das moléculas e equilíbrio entre síntese e degradação proteica. Assim, parece diretamente envolvido nas modificações relacionadas ao TR.

Coletivamente, esses resultados mostraram que o envelhecimento e 0 TR podem afetar diferentes estruturas do músculo esquelético pela alteração da transcrição de proteínas, matriz extracelular, resposta ao estresse e sarcômero, levando a mudanças morfológicas, metabólicas e alteração no conteúdo de proteína (figura 7).

Finalmente, é importante enfatizar que a maioria dos dados proteômicos advém de técnicas baseadas em análise gel com ionização e dessorção a laser assistida por matriz (MALDI) ou com análise de cromatografia líquida acoplada a espectrômetro de massas (LC-MS/MS) (Petriz et al, 2012). Porém, nenhum estudo usou a técnica "gel free" para análise de ratos idosos após o TR. Assim, a análise proteômica por meio do LC-ESI-MS/MS pode ser uma ferramenta para auxiliar no entendimento dos processos biológicos e mecanismos do TR no processo de envelhecimento. 


\subsection{CONCLUSÃO}

Em resumo, o presente estudo demonstrou que 12 semanas de treinamento resistido em ratos modula proteínas que favorecem as adaptações benéficas celulares ao exercício. Porém, a inatividade, representada pelo sedentarismo, promoveu aumento de proteínas que podem levar ao maior comprometimento do tecido muscular. $\mathrm{O}$ treinamento dos animais velhos conseguiu aumentar a AST quando comparado ao seu controle sedentário, por meio da regulação de proteínas metabólicas e antioxidantes importantes para a manutenção da integridade muscular esquelética. 


\section{REFERÊNCIAS}

Ballak S.B, Degens, H, de Haan A, Jaspers R.T. Aging related changes in determinants of muscle force generating capacity: A comparison of muscle aging in men and male rodents. Ageing Res Rev.14:43-55. doi: 10.1016/j.arr.2014.01.005 (2014).

Baraibar A. M.; Gueuguineau, M.; Duguez, S.; Butler-Brownie, G.; Bechet, D.;Friguet, B. Expression and modifications proteomics during skeletal muscle ageing. Biogentorology. 2013; (14). 339-352.

Barbosa et al, 2012. Proteômica: metodologias e aplicações no estudo de doenças humanas. Rev Assoc Med Bras; 58(3):366-375. 2012

Bautmans, I, et al. Biochemical Changes in Response to Intensive Resistance Exercise Training in the Elderly. Gerontol. 51:253-265 (2005).

Bearden, S.E. Effect of aging on the structure and function of skeletal muscle microvascular networks. Microcirculation, Jun; 13 (4):279-88 (2006).

Burniston J. Changes in the rat skeletal muscle proteome induced by moderate-intensity endurance exercise. Biochimica et Biophysica Acta 1784. 1077-1086 (2008).

Burniston, J.G; Connolly J, Kainulainen H, Britton, S.L, Koch, L.G. Label-free profiling of skeletal muscle using high-definition mass spectrometry. Proteomics. 14(20): 2339-2344 (2014).

Carvalho Tb.; Yamada Ak.; Crepaldi Md.; Souza Jc.; Prestes J.; Verlengia R. Treinamento de força excêntrico em idosos: revisão acerca das adaptações fisiológicas agudas e crônicas. R. bras. Ci. e Mov .2012;20(4):112-121.

Cederholm, TE et al. Toward a Definition of Sarcopenia. Clin Geriatr Med 27 (2011) 341-353.

Cuthbertson, D et al. Anabolic signaling deficits underlie amino acid resistance of wasting, aging muscle. The FASEB Journal. December 13, 2004. P.1-22.

Doran P, O'Connell, K, Gannon, J, Kavanagh, M, Ohlendieck K. Opposite pathobiochemical fate of pyruvate kinase and adenylate kinase in aged rat skeletal muscle as revealed by proteomic DIGE analysis. Proteomics 8, 364377 (2008).

Doria,E; Buonocore,D; Focarelli, A; Marzatico,F. Relationship between Human AgingMuscle and Oxidative System Pathway. Oxid Med and Cell Longev. V. 2012, Article ID 830257, 1-13. 2012. 
Durigan, J.L, et al. Neuromuscular electrical stimulation alters gene expression and delays quadriceps muscle atrophy of rats after anterior cruciate ligament transection. Muscle Nerve. 49(1):120-8 (2014).

Evans W. Functional and metabolic consequences of sarcopenia (1997) J Nutr, 127: 998S-1003S.

Fiatarone MA., Marks EC., Ryan ND., Meredith CN., Lipsitz LA., Evans WJ. High-intensity strength training in nonagenarians. Effects on skeletal muscle. JAMA 1990;263:3029-3034.

Fontana, $\mathrm{S}$ et al. Reduction in $\mathrm{mdx}$ mouse muscle degeneration by lowintensity endurance exercise: a proteomic analysis in quadriceps muscle of exercised compared with sedentary mdx mice. Biosci Rep. 35(3) (2015).

Freiberger WR, Sieber C, Pfeifer K. Physical activity, exercise and sarcopenia-future chalenges. Wien Med Wochensch, 2011;161:416-425.

Frontera, R.F; Ochala J. Skeletal Muscle: A Brief Review of Structure and Function. Calcif Tissue Int; 96:183-195 (2015).

Gandra et al. Proteomic profiling of skeletal muscle in an animal model of overtraining. Proteomics.12, 2663-2667. (2012).

Gannon, J. Ohlendieck, K. Subproteomic analysis of basic proteins in aged skeletal muscle following offgel pre-fractionation. Mol med Rep. 5: 993$1000,(2012)$.

Gannon, J.; Stauton, L.; O'Connell, K.; Doran, P.; Ohlendieck, K. Phosphoproteomic analysis of aged skeletal muscle. International Journal of Molecular Medicine. 2008; (22): 33-42 .

Gault, ML; Willems, MET. Aging, Functional Capacity and Eccentric Exercise Training. Aging e Disease. Volume 4, Number 6; 351-363, December 2013.

Gelfi C, et al. 2-D protein maps of rat gastrocnemius and soleus muscles: A tool for muscle plasticity assessment. Proteomics.6, 321-340 (2006).

Gelfi C, et al. The Human Muscle Proteome in Aging. J. Proteome Res. 5 (6), p 1344-1353 (2006).

Gelfi, C. Vasso, M. Cerretelli, P. Diversity of human skeletal muscle in health and disease:Contribution of proteomics. J Proteomics. 74: 774-795 (2011).

Gueugneau M, et al. Proteomics of muscle chronological ageing in postmenopausal women. BMC Genomics. Dec 23;15:1165. doi: 10.1186/14712164-15-1165 (2014).

Han, M. Kim, J. Effect of Dietary iron loading on recognition memory in growing rats. PLoS One. 2. Mar 6;10(3):e0120609. doi: 10.1371/journal.pone.0120609. e Collection (2015). 
Hakkinen et al. Selective muscle hypertrophy, changes in EMG and force, and serum hormones during strength training in older women. J Appl Physiol 91: 569-580, 2001.

Ishii,T, Warabi, E, Yanagawa, T. Novel roles of peroxiredoxins in inflammation, cancer and innate immunity. J. Clin. Biochem. Nutr. March 2012. vol. 50. numero. 2. p 91-105.

Järvinen TA, et al. Mechanical loading regulates the expression of tenascin-C in the myotendinous junction and tendon but does not induce de novo synthesis in the skeletal muscle. J Cell Sci.; 116: 857-866. 2003.

Kjaer, M. Role of extracellular matrix in adaptation of tendon and skeletal muscle to mechanical loading. Physiol Ver. 84: 649-698. 10.1152/physrev.00031.2003 (2004).

Kumar V, et al. Age-related differences in the dose-response relationshipof muscle protein synthesis to resistance exercise in young and old men. Physiol 587.1 (2009) pp 211-217.

LeBrasseur N.K, Walsh K, Arany Z. Metabolic Benefits of resistance training and fast glycolytic skeletal muscle. Am J Physiol Endocrinol Metab. Jan;300(1):E3-10. doi: 10.1152/ajpendo.00512.2010. Epub 2010 Nov 2 (2011).

Lourenço dos Santos S, Baraibar M.A, Lundberg S, Eeg-Olofsson O, Larsson L, Friguet B. Oxidative proteome alterations during skeletal muscle ageing. Redox Biol.5:267-274. doi:10.1016/j.redox.2015.05.006 (2015).

Magherini, F.; Gamberi, T.; Pietrovito, L.; Fiaschi, T.; Bini, L.; Esposito, F.; Marini, M.; Abruzzo, P.; Gulisano, M.; Modesti, A. Proteomic and Carbonylation Profile Analysis of Rat Skeletal Muscles following Acute Swimming Exercise. Journal of Proteomics. 2012. (75):978-992.

Mann, C.J. Aberrant repair and fibrosis development in skeletal muscle. $\begin{array}{lll}\text { Skeletal } & \text { Muscle, } & 1: 21 .\end{array}$ http://www.skeletalmusclejournal.com/content/1/1/21.

Marzetti $E$ et al. Mitochondrial dysfunction and sarcopenia of aging: from signaling pathways to clinical trials. Int J Biochem Cell Biol. Oct;45(10):2288301. doi: 10.1016/j.biocel.2013.06.024. Epub 2013 Jul 8. (2013).

May C, B F et al. Instruments and methods in proteomics. Methods Mol Biol.;696:3-26.

2011

Mayer F, Scharhag-Rosenberger F, Carlsohn A, Cassel M, Müller S, Scharhag, J. The Intensity and Effects of Strength Training in the Elderly. Dtsch Arztebl Int. 2011; 108: 359-364. 
Mitchell WK, Williams J, Athertone P, et al. Sarcopenia, dynapenia, and the impact of advancing age on human skeletal muscle size and strength; a quantitative review. Frontiers in Physiology 2012;3:260-78.

Mitchell,C.J, Churchward-Venne, C.A, Bellamy,L, Parise,G, Baker,C.K, Phillips S.M. Muscular and systemic correlates of resistance training-induced muscle hypertrophy. Plos One. http://dx.doi.org/10.1371/journal.pone.0078636 (2013).

Narici, M; Mafuli, N. Sarcopenia: characteristics, mechanisms and functional significance. British Medical Bulletin; 95: 139-159. 2010.

Narici, M; Mafuli, N. Ageing of human muscles and tendons. Disability and Rehabilitation. 30(20-22): 1548 - 1554. 2008.

Nilwik, RST; Leenders, M; Bart B,. Groen, Janneau van Kranenburg, Lex B. Verdijk, LJC. van Loon. The decline in skeletal muscle mass with aging is mainly attributed to a reduction in type II muscle fiber size. Exp. Gerontol; 48, 492-498. 2013

Norheim, F, Raastad, T.; Thiede, B.; Rustan, AC.; Drevon, CA.; Haugen, F. Proteomic identification of secreted proteins from human skeletal muscle cells and expression in response to strength training. Am J Physiol Endocrinol Metab. 301:E1013-E1021 (2011).

Nyström T, Yang J, Molin M. Peroxiredoxins, gerontogenes linking to genome instability and cancer. Genes Dev. 15, 26(18):2001-8. doi: 10.1101/gad.200006.112 (2012)

O'Connell k, Ohlendieck k. Proteomic DIGE analysis of the mitochondriaenriched fraction from aged rat skeletal muscle. Proteomics. 9, 5509-5524 (2009).

O'Connell, K.; Gannon, J.; Doran, P.; Ohlendieck, K. Proteomic profiling reveals a severely perturbed protein expression pattern in aged skeletal muscle. International Journal of Molecular Medicine. 2007 (20): 145-153.

Ohlendieck, K. Proteomic profiling of skeletal muscle plasticity. Muscles, Ligaments and Tendons Journal. 1 (4): 119-126, 2011.

Ohlendieck, K. Proteomics of skeletal muscle glycolysis. Biochimica et Biophysica ACTA.1804, 11, 2089-2101 (2010).

Pastoris, $O$ et al. The effects of aging on enzyme activities and metabolite concentrations in skeletal muscle from sedentary male and female subjects. Experimental Gerontology 35 (2000) 95-104.

Paterson D, Warburton D. Physical activity and functional limitations in older adults: a systematic review related to Canada's Physical Activity Guidelines. I J Behav Nut Phys Act 2010; 7(38). 
Petriz, B, A.; Gomes, C, L.; Rocha, L, A, O.; Rezende, M.B.; Franco, O, L. Proteomics Applied to Exercise Physiology: A Cutting-Edge Technology. J. Cell. Physiol. 2012 (227): 885-898.

Pette D, 1990 abud Minamoto VB. Classificação e adaptações das fibras musculares: uma revisão. Fisioterapia e Pesquisa. 2005; (12): 50-55.

Powers, SK; Jackson, MJ. Exercise-Induced Oxidative Stress: Cellular Mechanisms and Impact on Muscle Force Production. Physiol Rev. VOL 88 . OCTOBER 2008

Radák Z, et al. Exercise training decreases DNA damage and increases DNA repair and resistance against oxidative stress of proteins in aged rat skeletal muscle. Pflugers Arch. Nov; 445(2):273-8. Epub 2002 Sep 13 (2002).

Ratamess NA, et al. Progression Models in Resistance Training for Healthy Adults. Med Sci Sports Exercise. 2009; 41: 687-708.

Röckl, K.; Witczak, C.; Goodyear, L. Signaling Mechanisms in Skeletal Muscle: Acute Responses and Chronic Adaptations to Exercise. NIH Public Acess. 60(3): 145-153, 2008.

Sabidó, E.; Selevsek, N.; Aebersold, R. Mass spectrometry-based proteomics for systems biology. Curr. Opin. Biotechnol. 2012; 23(4):591-7.

Sakellariou, GK et al. Role of superoxide-nitric oxide interactions in the accelerated age-related loss of muscle mass in mice lacking $\mathrm{Cu}, \mathrm{Zn}$ superoxide dismutase. Aging Cell (2011) 10, pp749-760.

Saladin KS. Anatomy Physiology: The Unity of Form and Function. Third Edition. New York: The McGraw-Hill Companies, 2003: 1120

Salanova M, et al. Disuse deterioration of human skeletal muscle challenged by resistive exercise superimposed with vibration: evidence from structural and proteomic analysis. FASEB J. (11):4748-63. doi: 10.1096/fj.14-252825. Epub 2014. (2013).

Sietsema, S.K, et al. Potential biomarkers of muscle injury after eccentric exercise. Biomarkers. 15(3): 249-258 (2010).

Silva MDP, Carvalho RF. Mecanismos celulares e moleculares que controlam o desenvolvimento e o crescimento muscular. Revista Brasileira de Zootecnia. 2007; (36): 21-31.

Son H.J., Kim H.J., Kim C.K. The effect of resistance and endurance exercise training on muscle proteome expression in human skeletal muscle. Biol. Sport. 29:121-127 (2012).

Souza RW et al. High-intensity resistance training with insufficient recovery time between bouts induce atrophy and alterations in myosin heavy chain 
content in rat skeletal muscle. Anat Rec (Hoboken). 294(8):1393-400. doi: 10.1002/ar.21428 (2011).

Souza et al, 2014. Resistance training improves body composition and increases matrix metalloproteinase 2 activity in biceps and gastrocnemius muscles of diet-induced obese rats. Clinics. 2014;69(4):265-270

Stauton, L.; Zweyer, M.; Swandulla, D.; Ohlendieck, K. Mass spectrometrybased proteomic analysis of middle-aged vs. aged vastus lateralis reveals increased levels of carbonic anhydrase isoform 3 in senescent human skeletal muscle. International Journal of Molecular Medicine. 2012 (30): 723733.

Stefanetti R.J, Zacharewicz E, Della Gatta P, Garnham A, Russell A.P, Lamon S. Ageing has no effect on the regulation of the ubiquitin proteasomerelated genes and proteins following resistance exercise. Front Physiol 5:30. doi:10.3389/fphys.2014.00030 (2014).

Stewart VH, Saunders, DH, Greig, CA. Responsiveness of muscle size and strength to physical training in very elderly people: a systematic review. Scand J Med Sci Sports. 2014 Feb;24(1):e1-10.

Sun, XX, De Vine, T, Challagundla, K.B, Dai, MS. Interplay between ribosomal protein $\mathrm{S} 27 \mathrm{a}$ and MDM2 protein in p53 activation in response to ribosomal stress. J Biol Chem. Jul 1; 286(26):22730-41. doi: 10.1074/jbc.M111.223651. Epub 2011 May 11 (2011).

Théron L, et al. Label-free Quantitative Protein Profiling of vastus lateralis Muscle During Human Aging. Mol Cell Proteomics. 283-294 (2014).

Verdijk L.B, et al. Skeletal muscle hypertrophy following resistance training is accompanied by a fiber type specific increase in satellite cell content in elderly Men. J Gerontol A Biol Sci Med Sci. 64(3):332-9. doi: 10.1093/gerona/gln050 (2009).

Williams GN, Higgins MJ, Lewek MD. Aging skeletal muscle: Physiologic changes and the effects of training. Phys Ther.2002;82:62-68.

Yeung, Y.G, Stanley, E.R. Rapid detergent removal from peptide samples with ethyl acetate for mass spectrometry analysis. Curr Protoc Protein Sci. Chapter 16:Unit 16.12. doi: 10.1002/0471140864.ps1612s59 (2010).

Yamaguchi W, Fujimoto E, Higuchi M, Tabata, I. A DIGE proteomic analysis for high-intensity exercise-trained rat skeletal muscle. J. Biochem. 2010;148(3):327-333 doi:10.1093/jb/mvq073

Yan, $Z$ et al. Regulation of exercise-induced fiber type transformation, mitochondrial biogenesis, and angiogenesis in skeletal muscle. J Appl Physiol 110: 264-274, 2011.

Yarasheski KE (2003). Exercise, aging, and muscle protein metabolism. J Gerontol A: Biol Sci Med Sci, 58(10): M918-922. 
Silva, F,O,C; Macedo, D,V.Exercício físico, processo inflamatório e adaptação: uma visão geral. Rev Bras Cineantropom Desempenho Hum; 2011, 13(4):320-328. DOI: 10.5007/1980-0037.2011v13n4p320. 
ANEXOS

\title{
ANEXO I - Aprovação do Comitê de Ética em Experimentação Animal
}

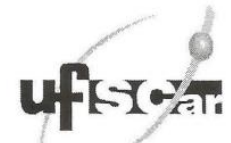 \\ UNIVERSIDADE FEDERAL DE SÃO CARLOS \\ PRÓ-REITORIA DE PESQUISA \\ Comissão de Ética no Uso de Animais \\ Via Washington Luis, km. 235 - Caixa Postal 676 \\ Fones: (016) 3351.8109 / 3351.8110 \\ Fax: (016) 3361.3176 \\ CEP 13560-970 - São Carlos - SP - Brasil \\ ceua@ufscar.br - www.propq.ufscar.br
}

Protocolo $n^{0} .056 / 2010$

A Presidente da Comissão de Ética no Uso de Animais da Universidade Federal de São Carlos - CEUA/UFSCar analisou e APROVOU "ad referendum" o pedido formulado pelo (a) pesquisador (a) Rita de Cassia Marqueti referente ao projeto "Matriz extracelular no envelhecimento e suas adaptações ao treinamento de força no tendão calcâneo de ratos: abordagem molecular, celular e biomecânica.".

São Carlos, 1 de março de 2011.

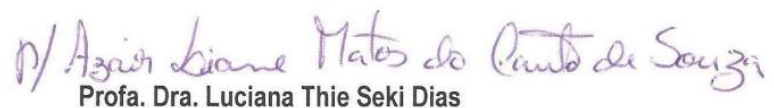

Profa. Dra. Luciana Thie Seki Dias

Presidente da Comissão de Ética no Uso de Animais 


\section{APÊNDICES}

APENDICE 1 - Proteinas expressas e alteradas pelo envelhecimento no musculo gastrocnêmio, agrupadas de acordo com suas funções biológicas

Nome da proteína

Processode

desenvolvimento/celular/metabólico

beta-enolase

anidrase carbônica 3

creatina cinase tipo $\mathrm{M}$

gliceraldeido-3-fosfato desidrogenase

glicose-6-fosfato isomerase

L-lactato desidrogenase cadeia A

fosfoglucomutase 1

fosfoglicerato cinase 1

fosfoglicerato mutase 2

triosefosfato isomerase

hemoglobina subunidade alfa-1/2

hemoglobina subunidade beta1

mioglobina

cadeia leve de miosina $1 / 3$

cadeia leve de miosina 2

\section{Resposta ao Estresse}

peroxiredoxina 1

proteina deglicase DJ 1

superóxido dismutase- $\mathrm{Cu}-\mathrm{Zn}$

$\mathbf{P}$

Proteinas com aumento de abundância.

$\begin{array}{ccc}\begin{array}{c}\text { Nome } \\ \text { primário }\end{array} & \text { Massa } & \text { valor de p } \\ & & \text { SJ x SV }\end{array}$

$\begin{array}{ccc}\text { ENOB_RAT } & 47,014 & 0,0001 \\ \text { CAH3_RAT } & 29,431 & 0,0001 \\ \text { KCRM_RAT } & 43,045 & 0,0001 \\ \text { G3P_RAT } & 35,828 & 0,0064 \\ \text { G6PI_RAT } & 62,827 & 0,0225 \\ \text { LDHA_RAT } & 36,451 & 0,0272 \\ \text { PGM1_RAT } & 61,403 & 0,0001 \\ \text { PGK1_RAT } & 44,538 & 0,0003 \\ \text { PGAM2_RAT } & 28,755 & 0,0001 \\ \text { TPIS_RAT } & 26,849 & 0,0001 \\ \text { HBA_RAT } & 15,329 & 0,0001 \\ \text { HBB1_RAT } & 15,979 & 0,0001 \\ \text { MYG_RAT } & 17,157 & 0,0001 \\ \text { MYL1_RAT } & 20,680 & 0,0001 \\ \text { MLRS_RAT } & 18,969 & 0,0002\end{array}$

PRDX1_RAT $\quad 22,109 \quad 0,0015$

PARK7_RAT $\quad 19,974 \quad 0,0001$

SODC_RAT $\quad 15,912 \quad 0,0001$ 
APENDICE II - Proteínas expressas alteradas pelo treinamento resistido no músculo gastrocnêmio, agrupados de acordo com suas funções biológicas.

\begin{tabular}{lccc}
\multicolumn{1}{c}{ Nome da Proteínas } & $\begin{array}{c}\text { Nome } \\
\text { primário }\end{array}$ & Massa & valor de p \\
PJ x TJ \\
Processode & & & \\
desenvolvimento/celular/metabólico & & & \\
beta-enolase & ENOB_RAT & 47,014 & 0,0001 \\
anidrase carbônica 3 & CAH3_RAT & 29,431 & 0,0001 \\
creatina cinase tipo M & KCRM_RAT & 43,045 & 0,0001 \\
frctose-bisfosfato aldolase A & ALDOA_RAT & 39,352 & 0,0001 \\
gliceraldeido-3-fosfato & & & \\
desidrogenase & G3P_RAT & 35,828 & 0,0001 \\
glicose-6-fosfato isomerase & G6PI_RAT & 62,827 & 0,0001 \\
L-lactato desidrogenase cadeia A & LDHA_RAT & 36,451 & 0,0001 \\
parvalbumina alfa & PRVA_RAT & 11,926 & 0,0001 \\
piyruvato cinase & KPYM_RAT & 57,818 & 0,0133 \\
fosfoglucomutase 1 & PGM1_RAT & 61,403 & 0,0002 \\
fosfoglicerato cinase 1 & PGK1_RAT & 44,538 & 0,0002 \\
fosfoglicerato mutase 2 & PGAM2_RAT & 28,755 & 0,0001 \\
triosefosfato isomerase & TPIS_RAT & 26,849 & 0,0001 \\
hemoglobina subunidade alfa-1/2 & HBA_RAT & 15,329 & 0,0001 \\
hemoglobina subunidade beta1 & HBB1_RAT & 15,979 & 0,0001 \\
mioglobina & MYG_RAT & 17,157 & 0,0157 \\
cadeia leve de miosina1/3 & MYL1_RAT & 20,680 & 0,0002 \\
cadeia leve de miosina 2 & MLRS_RAT & 18,969 & 0,0001 \\
Resposta ao Estresse & & & \\
proteina deglicase DJ 1 & PARK7_RAT & 19,974 & 0,0001 \\
superóxido dismutase-Cu-Zn & SODC_RAT & 15,912 & 0,0001
\end{tabular}

Proteínas com aumento de abundância. 
APENDICE III - Proteínas expressas alteradas no músculo gastrocnêmio de ratos velhos após treinamento resistido, agrupados de acordo com suas funções biológicas.

\begin{tabular}{|c|c|c|}
\hline Nome da proteína & $\begin{array}{l}\text { Nome } \\
\text { primário }\end{array}$ & Massa \\
\hline
\end{tabular}

\section{Processode}

desenvolvimento/celular/metabólico

\begin{tabular}{lccc} 
beta-enolase & ENOB_RAT & 47,014 & 0,0001 \\
anidrase carbônica 3 & CAH3_RAT & 29,431 & 0,0001 \\
frctose-bisfosfato aldolase A & ALDOA_RAT & 39,352 & 0.0466 \\
gliceraldeido-3-fosfato desidrogenase & G3P_RAT & 35,828 & 0,0001 \\
glicose-6-fosfato isomerase & G6PI_RAT & 62,827 & 0,0001 \\
piyruvato cinase & KPYM_RAT & 57,818 & 0,001 \\
fosfoglucomutase 1 & PGM1_RAT & 61,403 & 0,0001 \\
\hline hemoglobina subunidade alfa-1/2 & HBA_RAT & 15,329 & 0,0004 \\
hemoglobina subunidade beta1 & HBB1_RAT & 15,979 & 0,0039 \\
mioglobina & MYG_RAT & 17,157 & 0,0004 \\
cadeia leve de miosina1/3 & MYL1_RAT & 20,680 & 0,0044 \\
\hline Resposta ao Estresse & & & \\
\hline peroxiredoxina 1 & PRDX1_RAT & 22,109 & 0,0281 \\
\hline superóxido dismutase-Cu-Zn & SODC_RAT & 15,912 & 0,0003
\end{tabular}

Proteínas com mudanças em suas abundâncias: aumentado (branco) ou reduzido (cinza). 